\title{
Transition-pathway models of atomic diffusion on fcc metal surfaces. II. Stepped surfaces
}

\author{
Sung Youb Kim \\ Department of Mechanical Engineering, Korea Advanced Institute of Science and Technology, Daejeon 305-701, Korea \\ In-Ho Lee \\ Korea Research Institute of Standards and Science, Daejeon 305-600, Korea \\ Sukky Jun* \\ Department of Mechanical Engineering, University of Wyoming, Laramie, Wyoming 82071, USA
}

(Received 7 June 2007; published 10 December 2007)

\begin{abstract}
Action-derived molecular dynamics was demonstrated in the companion paper (Paper I) to be effective for the analysis of atomic surface diffusion. The method is here applied to the search of minimum-energy paths and the calculation of activation energy barriers in more complex single-adatom diffusion processes on fcc metal surfaces containing steps. Diverse diffusion routes are investigated along and across one- or two-layer steps on different surface orientations. Fundamental diffusion mechanisms near the step corners are also studied. Results are analyzed in relation to the island growth mechanism, which is of importance to surface nanoengineering.
\end{abstract}

DOI: 10.1103/PhysRevB.76.245408

PACS number(s): 68.35.Fx, 68.47.De, 82.20.Kh, 02.70.Ns

\section{INTRODUCTION}

In this series of papers, we demonstrate the robustness of the action-derived molecular dynamics (ADMD) for surface diffusion problems. ADMD has been utilized for the simulation of various multiple time scale problems as introduced in Paper $\mathrm{I},{ }^{1}$ and surface diffusion phenomena are among those where several different time scales are involved. ${ }^{2}$ The method can provide us an effective algorithm to search the pathways of diffusion process. ADMD suggests a modified action to minimize in finding dynamic pathways that approximately fulfill the Newtonian trajectory, which enables us to evaluate the accurate activation energy barrier along the minimum-energy path because it premises the given initial and final configurations.

By the action minimization with kinetic-energy control, ${ }^{3}$ we compute the minimum-energy paths and the associated activation energy barriers when one or more absorbates diffuse on the substrate of face-centered cubic (fcc) crystal structure. We focus on most probable diffusive motions of adatoms on these popular metal surfaces because our primary purpose is to verify the effectiveness of ADMD simulation for surface diffusions. Finding a novel diffusion path on less explored substrates is beyond the current scope of the paper, and is instead underway for our future reports. We consider six fcc metals, i.e., $\mathrm{Ni}, \mathrm{Cu}, \mathrm{Pd}, \mathrm{Ag}, \mathrm{Pt}$, and $\mathrm{Au}$, and three low Miller indices, i.e., (001), (111), and (110), for substrate models. Various mechanisms on flat surfaces have been investigated in Paper I. ${ }^{1}$

In this paper we present ADMD simulation of the diffusion processes on stepped surfaces. These phenomena are closely connected to the island growth mechanism, which is of great importance to nanoengineering since steps are inevitable in real processes of crystal growth. There are two main issues relevant to the diffusion mechanism across (or along) step edges and around step corners. The first one is the morphological shape of an island growing on the flat surface. The competition between moving toward the step and smoothing the step edges determines the final shape of the island. If smoothing events are dominant, the island has a compact shape. ${ }^{4-7}$ On the other hand, the fractal shapes of the island are formed when smoothing events are not active. The atomic motions along the steps or across the step corners (or edges) are important diffusion processes especially in characterizing the smoothing events.

The other issue is the island growth itself. When the descending motion from a position on terrace has a low activation energy barrier, the surface tends to be flattened, and the layer-by-layer growth becomes dominant. On the other hand,
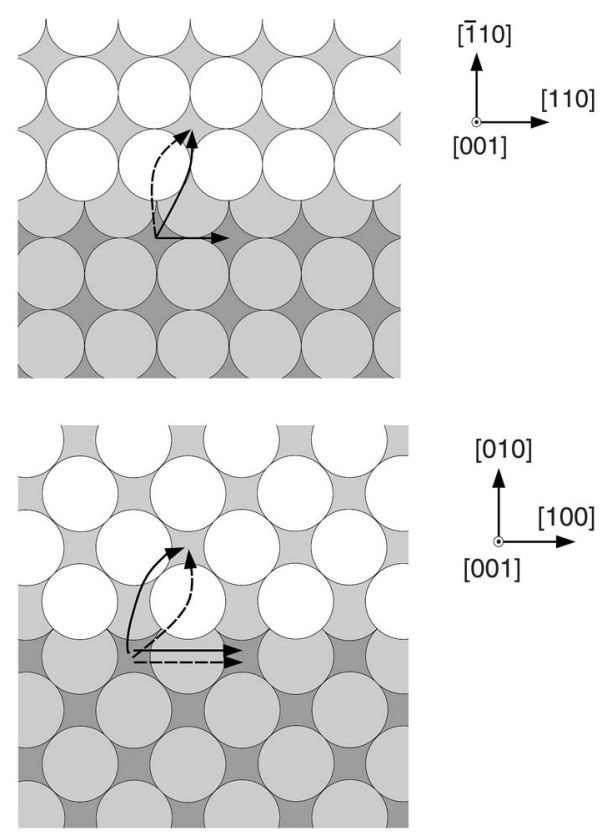

FIG. 1. Diffusion directions on stepped (001) surfaces. [110] step on the (001) surface (top) and [100] step on the (001) surface (bottom). 
TABLE I. Activation energy barriers (eV) of diffusions on the single-stepped (001) surface. For all tables in this paper, the value of the first row is the barrier of the climb reaction (ascending) and the values in parentheses are the barrier of reverse reactions (descending). The Ehrlich-Schwoebel (ES) barriers are given in the third row. When the ES barrier is negative, we set the value to zero.

\begin{tabular}{|c|c|c|c|c|c|c|c|}
\hline $\begin{array}{l}\text { Step } \\
\text { directions }\end{array}$ & Mechanisms & $\mathrm{Ni}$ & $\mathrm{Cu}$ & $\mathrm{Pd}$ & $\mathrm{Ag}$ & $\mathrm{Pt}$ & $\mathrm{Au}$ \\
\hline \multirow[t]{7}{*}{$\begin{array}{l}{[110]} \\
\text { step }\end{array}$} & $\begin{array}{l}\text { Parallel hopping } \\
\text { along the step }\end{array}$ & 0.253 & 0.269 & 0.354 & 0.261 & 0.514 & 0.326 \\
\hline & Vertical exchange & 1.191 & 0.922 & 0.924 & 0.778 & 1.134 & 0.610 \\
\hline & across the step & $(0.509)$ & $(0.559)$ & $(0.712)$ & $(0.557)$ & $(0.910)$ & $(0.515)$ \\
\hline & & 0.133 & 0.082 & 0.091 & 0.090 & 0.108 & 0.127 \\
\hline & Vertical hopping & 1.401 & 1.078 & 0.940 & 0.815 & 1.209 & 0.707 \\
\hline & across the step & $(0.718)$ & $(0.716)$ & $(0.728)$ & $(0.594)$ & $(0.985)$ & $(0.613)$ \\
\hline & & 0.342 & 0.239 & 0.107 & 0.127 & 0.183 & 0.225 \\
\hline \multirow{8}{*}{$\begin{array}{l}{[100]} \\
\text { step }\end{array}$} & Parallel exchange & 1.297 & 0.869 & 0.933 & 0.774 & 1.137 & 0.605 \\
\hline & $\begin{array}{l}\text { Parallel hopping } \\
\text { along the step }\end{array}$ & 0.615 & 0.772 & 0.941 & 0.719 & 1.397 & 0.802 \\
\hline & Vertical exchange & 1.240 & 0.943 & 0.901 & 0.766 & 1.120 & 0.606 \\
\hline & across the step & $(0.424)$ & $(0.349)$ & $(0.430)$ & $(0.335)$ & $(0.557)$ & $(0.322)$ \\
\hline & & 0.048 & 0.000 & 0.000 & 0.000 & 0.000 & 0.000 \\
\hline & Vertical hopping & 1.340 & 1.146 & 1.118 & 0.935 & 1.458 & 0.824 \\
\hline & across the step & $(0.525)$ & $(0.552)$ & $(0.647)$ & $(0.504)$ & $(0.895)$ & $(0.540)$ \\
\hline & & 0.149 & 0.075 & 0.026 & 0.037 & 0.093 & 0.152 \\
\hline
\end{tabular}

if the activation energy barrier of the descending diffusion is high enough, atoms are stacked on terraces, and then individual islands begin to grow. In most cases of across-step diffusions, there is an additional energy barrier because the coordination number of atoms is low at the transition states

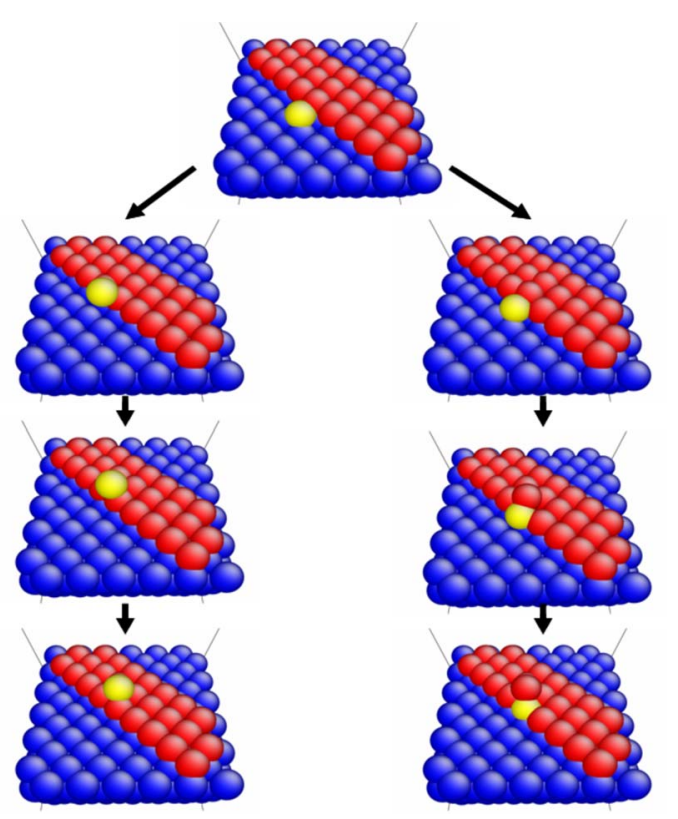

FIG. 2. (Color online) Pathway snapshots of an adatom diffusion across the step. Hopping-type climbing (left) and exchangetype climbing (right). of the crossing events. It is named the Ehrlich-Schwoebel (ES) barrier ${ }^{8,9}$ and is accordingly computed in the numerical examples of this paper. The low ES barrier means that the surface becomes easily flattened rather than forms an island. $^{4-7}$
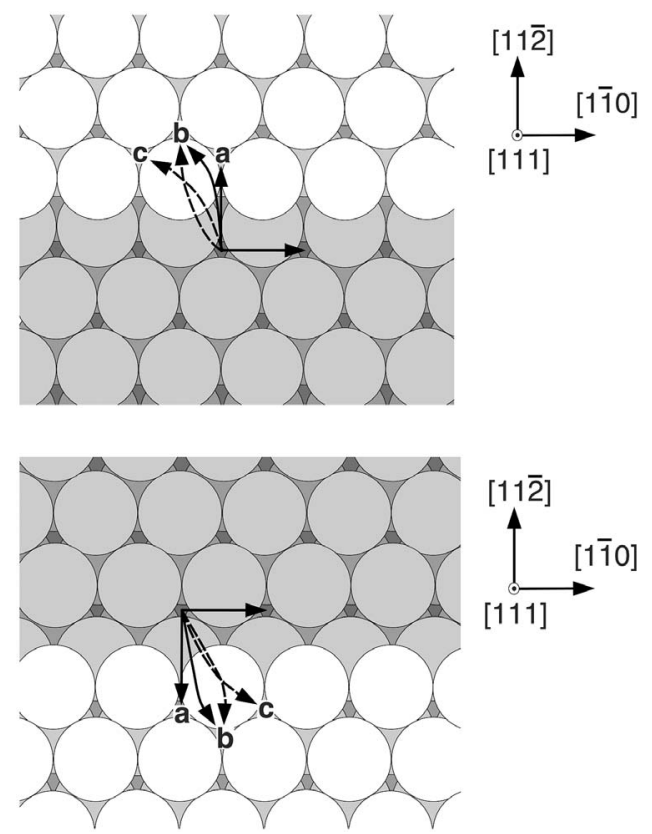

FIG. 3. Diffusion directions on stepped (111) surfaces. A-type step on the (111) surface (top) and $B$-type step on the (111) surface (bottom). 
TABLE II. Activation energy barriers (eV) of diffusions on the single-stepped (111) surface.

\begin{tabular}{|c|c|c|c|c|c|c|c|}
\hline $\begin{array}{l}\text { Step } \\
\text { directions }\end{array}$ & Mechanisms & $\mathrm{Ni}$ & $\mathrm{Cu}$ & $\mathrm{Pd}$ & $\mathrm{Ag}$ & $\mathrm{Pt}$ & $\mathrm{Au}$ \\
\hline \multirow[t]{13}{*}{$\begin{array}{l}A \text {-type } \\
\text { step }\end{array}$} & $\begin{array}{l}\text { Parallel hopping } \\
\text { along the step }\end{array}$ & 0.158 & 0.245 & 0.364 & 0.258 & 0.536 & 0.352 \\
\hline & Vertical exchange & 1.255 & 0.978 & 0.999 & 0.832 & 1.241 & 0.671 \\
\hline & across the step (to c) & $(0.286)$ & $(0.318)$ & $(0.444)$ & $(0.344)$ & $(0.535)$ & $(0.282)$ \\
\hline & & 0.225 & 0.275 & 0.335 & 0.280 & 0.364 & 0.165 \\
\hline & Vertical exchange & 1.256 & 0.978 & 0.999 & 0.832 & 1.241 & 0.673 \\
\hline & across the step (to b) & $(0.393)$ & $(0.368)$ & $(0.442)$ & $(0.344)$ & $(0.514)$ & $(0.262)$ \\
\hline & & 0.332 & 0.325 & 0.333 & 0.280 & 0.343 & 0.145 \\
\hline & Vertical hopping & 1.415 & 1.080 & 0.947 & 0.821 & 1.221 & 0.691 \\
\hline & across the step (to a) & $(0.445)$ & $(0.420)$ & $(0.393)$ & $(0.333)$ & $(0.516)$ & $(0.302)$ \\
\hline & & 0.384 & 0.377 & 0.284 & 0.269 & 0.345 & 0.185 \\
\hline & Vertical hopping & 1.416 & 1.081 & 0.947 & 0.821 & 1.222 & 0.687 \\
\hline & across the step (to b) & $(0.553)$ & $(0.472)$ & $(0.390)$ & $(0.348)$ & $(0.496)$ & $(0.276)$ \\
\hline & & 0.492 & 0.429 & 0.281 & 0.284 & 0.325 & 0.159 \\
\hline \multirow[t]{13}{*}{$\begin{array}{l}B \text {-type } \\
\text { step }\end{array}$} & $\begin{array}{l}\text { Parallel hopping } \\
\text { along the step }\end{array}$ & 0.385 & 0.309 & 0.381 & 0.302 & 0.461 & 0.237 \\
\hline & Vertical exchange & 0.940 & 0.763 & 0.848 & 0.674 & 1.113 & 0.638 \\
\hline & across the step (to c) & $(0.001)$ & $(0.095)$ & $(0.295)$ & $(0.181)$ & $(0.424)$ & $(0.272)$ \\
\hline & & 0.000 & 0.052 & 0.186 & 0.117 & 0.253 & 0.155 \\
\hline & Vertical exchange & 0.926 & 0.763 & 0.849 & 0.674 & 1.113 & 0.629 \\
\hline & across the step (to b) & $(0.092)$ & $(0.143)$ & $(0.296)$ & $(0.197)$ & $(0.408)$ & $(0.244)$ \\
\hline & & 0.031 & 0.100 & 0.187 & 0.133 & 0.237 & 0.127 \\
\hline & Vertical hopping & 1.368 & 1.091 & 0.943 & 0.825 & 1.201 & 0.659 \\
\hline & across the step (to a) & $(0.436)$ & $(0.423)$ & $(0.391)$ & $(0.332)$ & $(0.512)$ & $(0.294)$ \\
\hline & & 0.375 & 0.380 & 0.282 & 0.268 & 0.341 & 0.177 \\
\hline & Vertical hopping & 1.368 & 1.092 & 0.944 & 0.825 & 1.201 & 0.663 \\
\hline & across the step (to b) & $(0.534)$ & $(0.473)$ & $(0.390)$ & $(0.348)$ & $(0.496)$ & $(0.278)$ \\
\hline & & 0.473 & 0.430 & 0.281 & 0.284 & 0.325 & 0.161 \\
\hline
\end{tabular}

In numerical examples, particular emphasis is placed on homoepitaxial system because the exchange could be the very important and popular mechanism for climbing over the step, and the exchange processes are relevant especially for homoepitaxial metallic systems, as noted by Ref. 4. For step edge cases, single-layer and double-layer steps are both considered. Diffusion also proceeds around step corners, and these across-the-step diffusions are usually very difficult to analyze by using the conventional molecular dynamics. As in Paper I, the tight-binding potential with second-moment approximation ${ }^{10}$ is used for the interaction between atoms, and the ATOMEYE software ${ }^{11}$ is used for a three-dimensional perspective visualization of atomic configuration.

This paper will be presented as follows. Single-layer steps and double-layer steps are considered in Secs. II and III, respectively. In each section, steps on (001), (111), and (110) substrates are modeled. Step corners are then considered in the following three sections, each of which is devoted to the step corners on (001), (111), and (110) surfaces in Secs. IV-VI, respectively. In each section, various diffusion motions are investigated in terms of minimum-energy paths and activation energy barriers.

\section{SINGLE-LAYER STEPS}

\section{A. Steps on (001) surfaces}

First, we simulate the single-adatom diffusion around the step edge of which the height is one atomic layer. Steps are identified by the direction of their edge. Two different step directions of low Miller indices are modeled on the (001) surface, as shown in Fig. 1. One is the [110] step, and the other is the [100] step. Six different atomic species, $\mathrm{Ni}, \mathrm{Cu}$, $\mathrm{Pd}, \mathrm{Ag}, \mathrm{Pt}$, and $\mathrm{Au}$, are considered. The islands of 36 and 30 atoms for the [110] step and [100] step, respectively, reside on the substrates of the same atomic species. Substrates are composed of 384 and 360 for the [110] step and [100] step, respectively. Diffusion directions are denoted by arrows in Fig. 1. Solid arrows indicate the direction of hopping, and dotted arrows that of exchange.

\section{Along the step edges}

The [110] step is the closest packed direction on the (001) surface, and only a hopping mechanism is possible along the step. The final position of hopping along the [110] step is the 

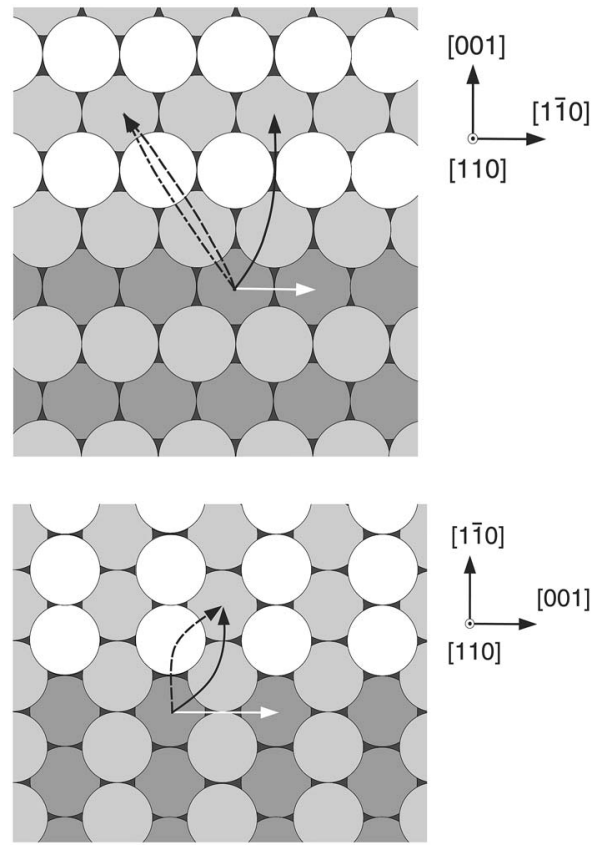

FIG. 4. Diffusion directions on stepped (110) surfaces. [1 $1 \overline{1} 0]$ step on the (110) surface (top) and [100] step on the (110) surface (bottom).

same as that on a flat surface. For the [100] step, both hopping and exchange are possible along the step, and their final positions along the [100] step are also the same as those on the flat surface.
The computed energy barriers of the diffusions along the [110] step and along the [100] step are given in Table I. The values for hopping along the [110] step significantly decrease compared with the flat-surface cases for all elements. For example, the value of $\mathrm{Cu}$ hopping is reduced from 0.48 to $0.27 \mathrm{eV}$. This means that adatom more frequently hops along the step than on the free (001) surface.

The hopping barriers along the [100] step are higher than those along the [110] step for all species. Meanwhile, the hopping barriers along the [100] step are lower than the exchange barriers along the [100] step for $\mathrm{Ni}, \mathrm{Cu}$, and $\mathrm{Ag}$, whereas exchange mechanism is more probable than hopping for Pt and Au. Hopping and exchange occur at nearly the same frequency in the case of Pd.

Barriers for exchange along the [100] step is higher than those on the flat surface for all but Ni. For example, the exchange barrier of $\mathrm{Cu}$ atom increases from 0.71 to $0.87 \mathrm{eV}$. We may conclude that when a single atom diffuses along the step on the (001) surface, the step plays the role of decreasing the hopping barriers and increasing the exchange barriers (except $\mathrm{Ni}$ ), compared with flat-surface cases.

\section{Across the step edges}

Both hopping and exchange motions can take place across the step. Their processes across the [110] step on the (001) surface are visualized in Fig. 2. The activation energy barriers across the steps are given also in Table I. The value of the first row is the barrier of the climb reaction (ascending), and the values in parentheses are the barrier of reverse reactions (descending). The ES barriers, which are defined by the dif-

TABLE III. Activation energy barriers (eV) of diffusions on the single-stepped (110) surface.

\begin{tabular}{lccccccc}
\hline \hline $\begin{array}{l}\text { Step } \\
\text { directions }\end{array}$ & Mechanisms & $\mathrm{Ni}$ & $\mathrm{Cu}$ & $\mathrm{Pd}$ & $\mathrm{Ag}$ & $\mathrm{Pt}$ & $\mathrm{Au}$ \\
\hline $\begin{array}{l}{[1 \overline{1} 0]} \\
\text { step }\end{array}$ & $\begin{array}{c}\text { Parallel hopping } \\
\text { along the step }\end{array}$ & 0.338 & 0.263 & 0.400 & 0.291 & 0.515 & 0.289 \\
& & & & & & & \\
& Vertical exchange & 0.852 & 0.732 & 0.844 & 0.655 & 1.147 & 0.691 \\
& across the step & $(0.606)$ & $(0.694)$ & $(0.871)$ & $(0.662)$ & $(1.194)$ & $(0.721)$ \\
& & 0.305 & 0.453 & 0.491 & 0.385 & 0.704 & 0.447 \\
& Double exchange & 0.995 & 0.856 & 1.060 & 0.832 & 1.373 & 0.776 \\
& across the step & $(0.749)$ & $(0.819)$ & $(1.088)$ & $(0.839)$ & $(1.420)$ & $(0.807)$ \\
& & 0.448 & 0.578 & 0.708 & 0.562 & 0.930 & 0.533 \\
& Vertical hopping & 1.398 & 1.094 & 0.951 & 0.833 & 1.225 & 0.715 \\
& across the step & $(1.151)$ & $(1.056)$ & $(0.978)$ & $(0.841)$ & $(1.272)$ & $(0.745)$ \\
& & 0.850 & 0.815 & 0.598 & 0.564 & 0.782 & 0.471 \\
step & Parallel hopping & 0.826 & 0.831 & 1.013 & 0.768 & 1.416 & 0.821 \\
& along the step & & & & & & \\
& Vertical exchange & 1.006 & 0.762 & 0.866 & 0.690 & 1.106 & 0.617 \\
& across the step & $(0.556)$ & $(0.511)$ & $(0.671)$ & $(0.514)$ & $(0.863)$ & $(0.484)$ \\
& & 0.255 & 0.270 & 0.291 & 0.237 & 0.373 & 0.210 \\
& Vertical hopping & 1.058 & 0.842 & 0.985 & 0.769 & 1.343 & 0.780 \\
& across the step & $(0.607)$ & $(0.592)$ & $(0.790)$ & $(0.592)$ & $(1.100)$ & $(0.647)$ \\
& & 0.306 & 0.351 & 0.410 & 0.315 & 0.610 & 0.373 \\
\hline \hline
\end{tabular}



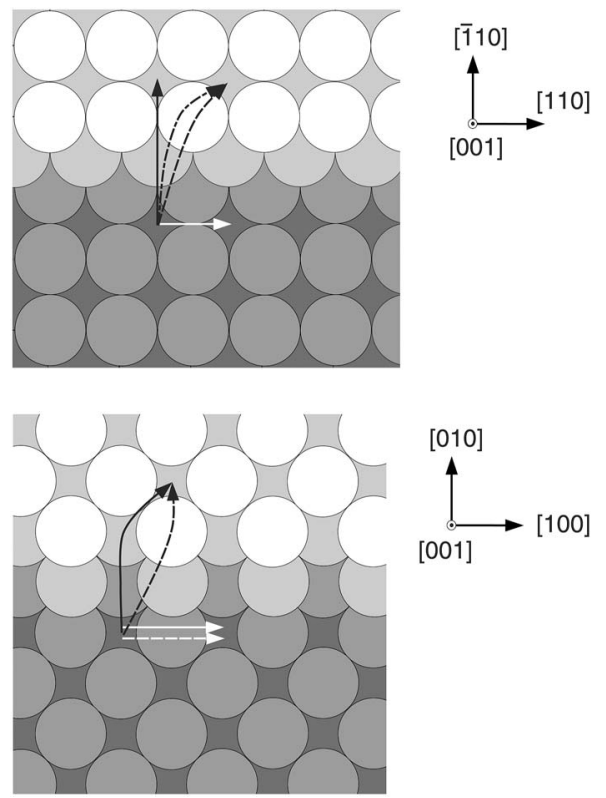

FIG. 5. Diffusion directions on double-stepped (001) surfaces. [110] step on the (001) surface (top) and [001] step on the (001) surface (bottom).

ference between the descending barriers across the step and the minimum diffusion barriers on the flat surface, are shown in the third row. When the ES barrier is negative, we set the value to zero. No additional calculation is necessary for a descending diffusion. ADMD simulation results have microscopic reversibility so that the initial and final configurations

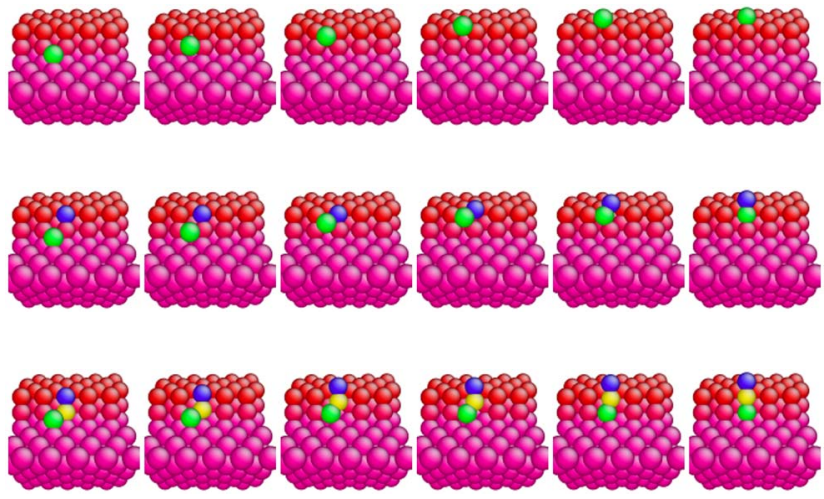

FIG. 6. (Color online) Pathway snapshots of climbing on a double-stepped surface. Hopping (top row), single exchange (middle row), and double exchange (bottom row). Each row proceeds from left to right.

are totally exchangeable. ${ }^{12}$ The activation energy barrier of a descending process is consequently identical to the energy difference between the final configuration and the transition state on the trajectory of the ascending counterpart.

In across-the-step diffusions, exchange mechanism is more favorable than hopping mechanism for both step directions regardless of the species. For $\mathrm{Cu}$, the barrier for exchange-type climbing is $0.16 \mathrm{eV}$ lower than that for hopping-type climbing across the [110] step. This difference is $0.20 \mathrm{eV}$ when $\mathrm{Cu}$ diffuses across the [100] step.

Exchange barriers across the [110] step are very close to those across the [100] step for all atomic elements. The

TABLE IV. Activation energy barriers (eV) of diffusions on double-stepped (001) surface.

\begin{tabular}{lccccccc}
\hline \hline Step directions & Mechanisms & $\mathrm{Ni}$ & $\mathrm{Cu}$ & $\mathrm{Pd}$ & $\mathrm{Ag}$ & $\mathrm{Pt}$ & $\mathrm{Au}$ \\
\hline [110] step & Parallel hopping along the step & 0.191 & 0.242 & 0.354 & 0.253 & 0.522 & 0.337 \\
& Vertical exchange & 1.634 & 1.061 & 1.099 & 0.951 & 1.458 & 1.020 \\
& across the step & $(0.767)$ & $(0.679)$ & $(0.886)$ & $(0.727)$ & $(1.226)$ & $(0.915)$ \\
& Double exchange & 0.391 & 0.202 & 0.265 & 0.260 & 0.424 & 0.527 \\
& across the step & 1.863 & 1.337 & 1.379 & 1.150 & 1.709 & 0.926 \\
& $(0.995)$ & $(0.956)$ & $(1.166)$ & $(0.926)$ & $(1.476)$ & $(0.822)$ \\
& Vertical hopping & 0.619 & 0.479 & 0.545 & 0.459 & 0.674 & 0.434 \\
across the step & 1.662 & 1.127 & 1.215 & 0.888 & 1.726 & 1.037 \\
& $(0.796)$ & $(0.746)$ & $(1.002)$ & $(0.664)$ & $(1.494)$ & $(0.932)$ \\
& Parallel exchange along the step & 1.322 & 0.925 & 0.973 & 0.811 & 1.190 & 0.631 \\
& Parallel hopping along the step & 0.658 & 0.762 & 0.973 & 0.712 & 1.379 & 0.807 \\
Vertical exchange & 1.510 & 0.982 & 0.904 & 0.782 & 1.136 & 0.646 \\
across the step & $(0.524)$ & $(0.379)$ & $(0.442)$ & $(0.356)$ & $(0.580)$ & $(0.361)$ \\
& & 0.148 & 0.000 & 0.000 & 0.000 & 0.000 & 0.000 \\
& Double exchange & 1.589 & 1.168 & 1.196 & 0.990 & 1.502 & 0.824 \\
across the step & $(0.603)$ & $(0.566)$ & $(0.734)$ & $(0.565)$ & $(0.945)$ & $(0.540)$ \\
& & 0.227 & 0.089 & 0.113 & 0.098 & 0.143 & 0.152 \\
& Vertical hopping & 1.508 & 1.146 & 1.111 & 0.950 & 1.475 & 0.874 \\
across the step & $(0.522)$ & $(0.543)$ & $(0.650)$ & $(0.524)$ & $(0.919)$ & $(0.590)$ \\
& & 0.146 & 0.066 & 0.029 & 0.057 & 0.117 & 0.202 \\
\hline \hline
\end{tabular}



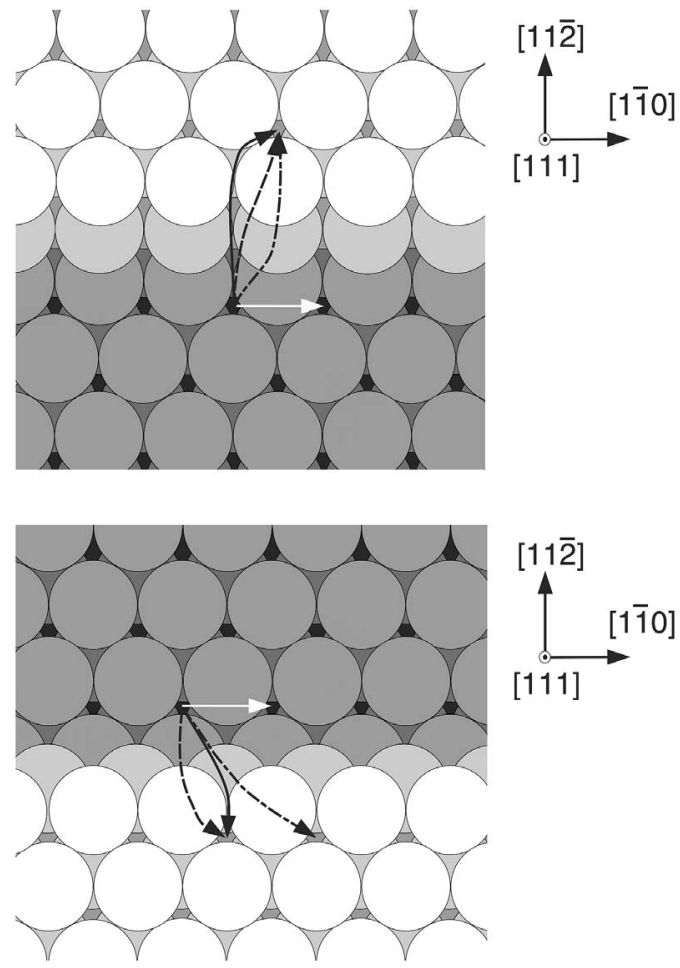

FIG. 7. Diffusion directions on double-stepped (111) surfaces. $A$-type step on the (111) surface (top) and $B$-type step on the (111) surface (bottom). maximum difference between them is $0.05 \mathrm{eV}$ for $\mathrm{Ni}$, and other elements are less than $0.02 \mathrm{eV}$. While ES barriers for the exchange across the [110] step are nonzero, those across the [100] step are zeros except for Ni, as shown in Table I. Especially, the barrier of $\mathrm{Pt}$ adatom for descending across the [100] step is significantly lower than that for exchange on the (001) flat surface. Table I implies that an island on the (001) surface tends to be flattened when its edge forms the [100] step. This agrees well with experimental results obtained by the reflection high-energy electron-diffraction intensity oscillation that observed the two-dimensional flat growth mode on $\operatorname{Ag}(001)$ surface. ${ }^{13}$

\section{B. Steps on (111) surfaces}

$\langle 110\rangle$ is the most dominant step direction on the (111) surface. However, as shown in Fig. 3, there are two types of the $\langle 110\rangle$ step although they have the same direction. A-type and $B$-type steps denote the $\{001\}$ and $\{111\}$ microfacets, respectively. The models consist of six atomic layers of 64 atoms, except the islands with 32 atoms, and thus the total number of atoms is 416 for both types of model. Probable directions of the single atom diffusion are depicted by solid and dotted arrows in Fig. 3 as in the previous example. Simulated are one hopping along the step two hoppings, and two exchanges across the step for both $A$ - and $B$-type steps.

\section{Along the step edges}

The activation energy barriers of hopping along the step edge significantly increase compared with those on free sur-

TABLE V. Activation energy barriers (eV) of diffusions on the double-stepped (111) surface.

\begin{tabular}{|c|c|c|c|c|c|c|c|}
\hline $\begin{array}{l}\text { Step } \\
\text { directions }\end{array}$ & Mechanisms & $\mathrm{Ni}$ & $\mathrm{Cu}$ & $\mathrm{Pd}$ & $\mathrm{Ag}$ & $\mathrm{Pt}$ & $\mathrm{Au}$ \\
\hline \multirow[t]{10}{*}{$\begin{array}{l}A \text {-type } \\
\text { step }\end{array}$} & $\begin{array}{l}\text { Parallel hopping } \\
\text { along the step }\end{array}$ & 0.180 & 0.247 & 0.346 & 0.248 & 0.499 & 0.316 \\
\hline & \multirow{3}{*}{$\begin{array}{l}\text { Vertical exchange } \\
\text { across the step }\end{array}$} & 1.682 & 1.047 & 1.002 & 0.855 & 1.236 & 0.694 \\
\hline & & $(0.666)$ & $(0.436)$ & $(0.459)$ & $(0.392)$ & $(0.527)$ & $(0.293)$ \\
\hline & & 0.605 & 0.393 & 0.350 & 0.328 & 0.356 & 0.176 \\
\hline & \multirow{3}{*}{$\begin{array}{l}\text { Double-exchange } \\
\text { across the step }\end{array}$} & 1.529 & 1.114 & 1.220 & 0.993 & 1.467 & 0.850 \\
\hline & & $(0.513)$ & $(0.503)$ & $(0.677)$ & $(0.530)$ & $(0.758)$ & $(0.449)$ \\
\hline & & 0.452 & 0.460 & 0.568 & 0.466 & 0.587 & 0.332 \\
\hline & \multirow{3}{*}{$\begin{array}{l}\text { Vertical hopping } \\
\text { across the step }\end{array}$} & 1.679 & 1.100 & 0.945 & 0.830 & 1.241 & 0.753 \\
\hline & & $(0.663)$ & $(0.489)$ & $(0.403)$ & $(0.367)$ & $(0.531)$ & $(0.351)$ \\
\hline & & 0.602 & 0.446 & 0.294 & 0.303 & 0.360 & 0.234 \\
\hline \multirow[t]{10}{*}{$\begin{array}{l}B \text {-type } \\
\text { step }\end{array}$} & $\begin{array}{l}\text { Parallel hopping } \\
\text { along the step }\end{array}$ & 0.382 & 0.325 & 0.425 & 0.325 & 0.544 & 0.300 \\
\hline & \multirow{3}{*}{$\begin{array}{l}\text { Vertical exchange } \\
\text { across the step }\end{array}$} & 1.504 & 1.010 & 0.959 & 0.802 & 1.228 & 0.689 \\
\hline & & $(0.245)$ & $(0.297)$ & $(0.424)$ & $(0.311)$ & $(0.564)$ & $(0.334)$ \\
\hline & & 0.184 & 0.254 & 0.315 & 0.247 & 0.393 & 0.217 \\
\hline & \multirow{3}{*}{$\begin{array}{l}\text { Double-exchange } \\
\text { across the step }\end{array}$} & 1.756 & 1.280 & 1.311 & 1.163 & 1.664 & 0.918 \\
\hline & & $(0.498)$ & $(0.568)$ & $(0.776)$ & $(0.672)$ & $(1.000)$ & $(0.563)$ \\
\hline & & 0.437 & 0.525 & 0.667 & 0.608 & 0.829 & 0.446 \\
\hline & \multirow{3}{*}{$\begin{array}{l}\text { Vertical hopping } \\
\text { across the step }\end{array}$} & 1.822 & 1.172 & 0.930 & 0.834 & 1.179 & 0.652 \\
\hline & & $(0.564)$ & $(0.459)$ & $(0.395)$ & $(0.343)$ & $(0.515)$ & $(0.297)$ \\
\hline & & 0.503 & 0.416 & 0.286 & 0.279 & 0.344 & 0.180 \\
\hline
\end{tabular}



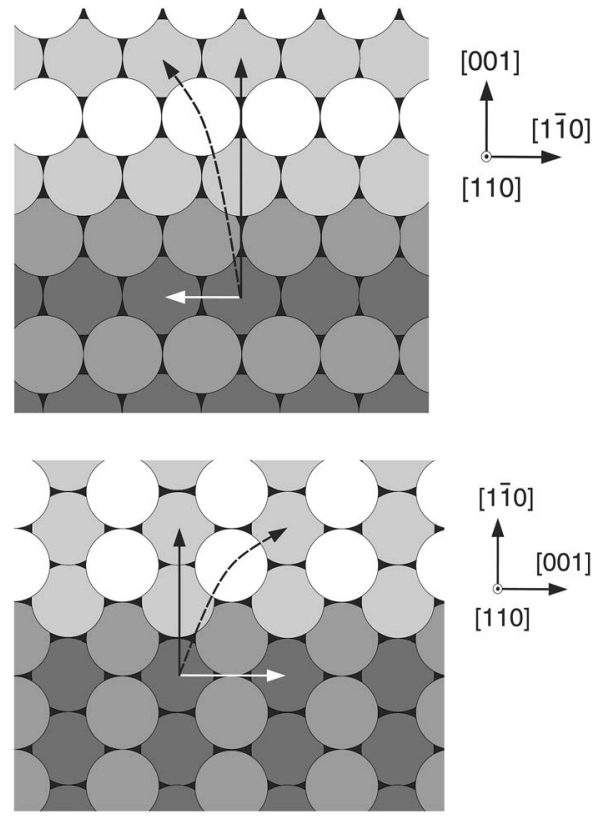

FIG. 8. Diffusion directions on double-stepped (110) surfaces. $[1 \overline{1} 0]$ step on the (110) surface (top) and [001] step on the (110) surface (bottom).

face, regardless of the step type and species, as given in Table II. In contrast to the (001) surface, the step hinders adatom hopping on the (111) surface to the direction along the step edges. For $\mathrm{Cu}$, the along-the-edge barriers are $0.25 \mathrm{eV}$ for $A$ type and $0.31 \mathrm{eV}$ for $B$ type. Both values are much greater than $0.04 \mathrm{eV}$, which is the barrier of the flatsurface case. The hopping barriers along the $A$-type step are lower than those along the $B$-type step for $\mathrm{Ni}, \mathrm{Cu}, \mathrm{Pd}$, and $\mathrm{Ag}$, while hopping along the $B$-type step is more frequent than that along the A-type step for Pt and Au. The dependence of energy barriers on the step type is due to the atomic structures around the hopping diffusion paths along the steps, as can easily be noticed in Fig. 3 .

\section{Across the step edges}

The energy barriers of climbing and descending are presented in Table II. The value on the third row is the ES barriers as in the previous example. The climbing by exchange to different positions reveals the same energy barrier of each for both types of the steps, which is also the case for the climbing by hopping. However, barriers of descending from the different positions by the same mechanism are slightly different from each other because the atomic coordination numbers of the adatom are not the same at the different positions on the terrace. For $\mathrm{Cu}$, whereas the barriers for climbing by exchange across the $A$-type step to positions $b$ and $c$ are both $0.98 \mathrm{eV}$, those of descending are $0.37 \mathrm{eV}$ from position $b$ and $0.32 \mathrm{eV}$ from position $c$. The cases of hopping mechanism reveal the same tendency for both step types.

In diffusions across the $B$-type step on the (111) surface, the exchange mechanism is more favorable than the hopping mechanism for both ascending and descending processes. Barriers for exchange across the $B$-type step are quite lower than those across the $A$-type step for all elements. The ES barriers for exchange across the $A$-type step lie in the range from 0.15 to $0.36 \mathrm{eV}$, and those across the $B$-type step are less than $0.25 \mathrm{eV}$. Especially, the ES barrier of $\mathrm{Ni}$ atom for descending by exchange across the $B$-type step is zero. In the $B$-type step, descending across the steps by hopping mechanism requires more energy than descending by exchange mechanism for all atomic elements, as shown in Table II. While the ES barriers for exchange are different depending

TABLE VI. Activation energy barriers (eV) of diffusions on the double-stepped (110) surface.

\begin{tabular}{lccccccc}
\hline \hline $\begin{array}{l}\text { Step } \\
\text { directions }\end{array}$ & Mechanisms & $\mathrm{Ni}$ & $\mathrm{Cu}$ & $\mathrm{Pd}$ & $\mathrm{Ag}$ & $\mathrm{Pt}$ & $\mathrm{Au}$ \\
\hline $\begin{array}{l}{[1 \overline{1} 0]} \\
\text { step }\end{array}$ & $\begin{array}{c}\text { Parallel hopping } \\
\text { along the step }\end{array}$ & 0.332 & 0.258 & 0.395 & 0.289 & 0.505 & 0.281 \\
& Vertical exchange & 1.001 & 0.748 & 0.848 & 0.672 & 1.142 & 0.721 \\
& across the step & $(0.699)$ & $(0.709)$ & $(0.872)$ & $(0.678)$ & $(1.180)$ & $(0.743)$ \\
& & 0.398 & 0.468 & 0.492 & 0.401 & 0.690 & 0.469 \\
& Vertical hopping & 1.459 & 1.097 & 1.240 & 0.933 & 1.739 & 1.060 \\
& across the step & $(1.157)$ & $(1.057)$ & $(1.264)$ & $(0.940)$ & $(1.776)$ & $(1.081)$ \\
& & 0.856 & 0.816 & 0.884 & 0.663 & 1.286 & 0.807 \\
[001] & Parallel hopping & 0.682 & 0.740 & 0.922 & 0.710 & 1.367 & 0.795 \\
step & along the step & & & & & & \\
& Vertical exchange & 1.400 & 0.956 & 0.916 & 0.772 & 1.260 & 0.753 \\
& across the step & $(0.830)$ & $(0.708)$ & $(0.736)$ & $(0.607)$ & $(1.033)$ & $(0.627)$ \\
& Vertical hopping & 1.394 & 1.288 & 1.546 & 1.202 & 2.121 & 1.265 \\
& across the step & $(0.823)$ & $(1.040)$ & $(1.366)$ & $(1.036)$ & $(1.894)$ & $(1.139)$ \\
& & 0.522 & 0.799 & 0.986 & 0.759 & 1.404 & 0.865 \\
\hline \hline
\end{tabular}




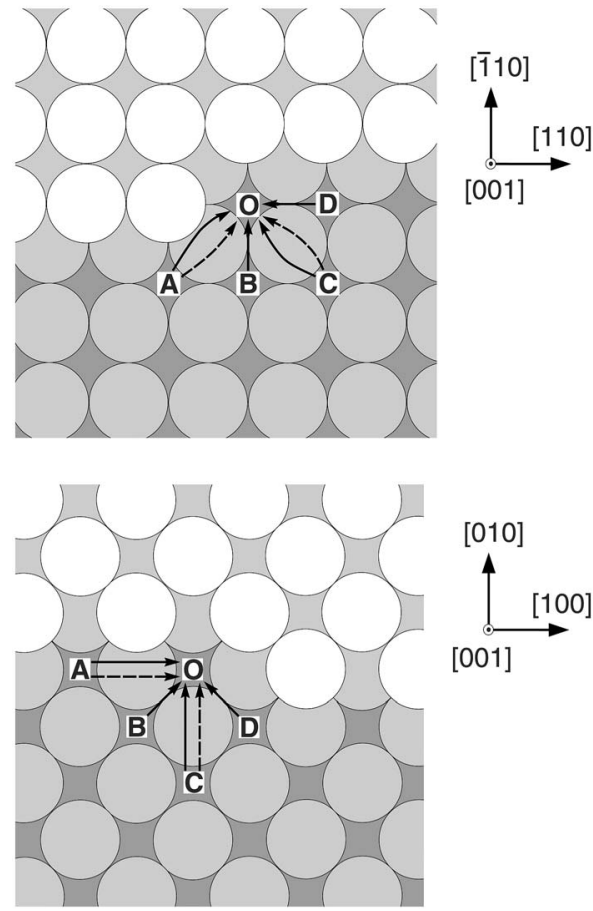

FIG. 9. Horizontal diffusion directions to the step corners on the (001) surface. Diffusion to the [110] step corner (top) and diffusion to the [100] step corner (bottom).

on the types of steps, those for hopping are nearly the same for both types of steps. The result that the ES barriers of the diffusion on the (111) surface are much higher than those on the (001) surface is in good agreement with the experimental observations that three-dimensional islands are more easily formed on the (111) surface than on the (001) surface for most fcc metals. ${ }^{6,14-16}$

\section{Steps on the (110) surfaces}

Two steps are frequently observed on the (110) surface. They are [1 $\overline{1} 0]$ and [001] steps along the in-channel and out-channel directions, as illustrated in Fig. 4. The models employed consist of eight atomic layers of 48 atoms except the islands that has 24 atoms. Therefore, 408 atoms are used in total for both steps. Diffusion directions of a single atom are presented by solid and dotted arrows in Fig. 4. A dashdotted arrow in Fig. 4 denotes a double-exchange mechanism in which the adatom pushes up a substrate atom by exchange and then the substrate atom subsequently pushes up an atom of the step. This double-exchange mechanism will be compared with the single-exchange move. Both mechanisms share the common initial and final configurations with each other. This type of double-exchange mechanism across a single-layered step is considered in this section only. Later in this paper, we imply by the double exchange a successive exchange move across the double-layered steps in which only atoms at each layer, not a substrate atom, are involved. Therefore, in the double-layer cases, the pathways will straightforwardly be imagined by the corresponding figures.

\section{Along the step edges}

The calculated energy barriers of the diffusions related with [1 $\overline{10}]$ and [001] steps are presented in Table III. The hopping barriers along the [1] 0$]$ step are higher than those along the flat (110) surface for all atomic elements. For $\mathrm{Cu}$, the barrier increases slightly from 0.24 to $0.26 \mathrm{eV}$. However, in the case of hopping along the [001] step, the changes of barriers compared with those of flat surface are species dependent. That is, for $\mathrm{Pd}, \mathrm{Pt}$, and $\mathrm{Au}$, the barriers for outchannel hopping increase, but decrease for $\mathrm{Ni}, \mathrm{Cu}$, and $\mathrm{Ag}$.

\section{Across the step edges}

Exchange moves are the most probable mechanism in the climbing diffusions across the [1 $\overline{1} 0]$ step for all species, as in the general cases of other surface orientations. For $\mathrm{Cu}$, the ES barrier of exchange motion is $0.45 \mathrm{eV}$, which is much lower than that of hopping, $0.82 \mathrm{eV}$. While the doubleexchange mechanism across the step needs more energy than the single exchange, it is more favorable than the hopping for $\mathrm{Ni}$ and $\mathrm{Cu}$. For $\mathrm{Cu}$, the ES barrier of the double exchange is $0.24 \mathrm{eV}$ lower than that of hopping. When the adatom diffuses across the [001] step, exchange is also more probable than hopping for all elements. For $\mathrm{Cu}$, the ES barrier of the exchange is $0.08 \mathrm{eV}$ lower than that of hopping. $\mathrm{Pt}$ and $\mathrm{Au}$ adatoms have the highest and the lowest ES barriers for the diffusion across the [001] step, respectively.

\section{DOUBLE-LAYER STEPS}

In this section, we conduct simulations for the single atom diffusion along and across the edges of double-layer steps. Results are analyzed in comparison with the cases of flat surface and single-layer steps.

\section{A. Steps on (001) surfaces}

Double-layer steps of [110] and [100] directions on the (001) surface are modeled as given in Fig. 5. 56 and 50 atoms are used for the islands, and 440 and 410 substrate atoms are employed for the cases of the [110] and [100] steps, respectively. The solid, dotted, and double-dotted arrows in Fig. 5 indicate a hopping, an exchange, and a double-exchange process, respectively. The difference between their pathways can be recognized with the arrows in the figure. Figure 6 shows the simulated atomic motions in typical diffusive processes of hopping and exchanges over a double-layered step. The perspective view of high angle is employed in order to focus on the routes of diffusion pathways.

\section{Along the step edges}

The obtained diffusion barriers related to the [110] and [100] steps are presented in Table IV. Along the [110] step, hopping barriers are much lower than those on the flat surface for all elements. However, they are slightly lower than those of a one-layer-height step for $\mathrm{Ni}, \mathrm{Cu}$, and $\mathrm{Ag}$, and a little higher for Pt and $\mathrm{Au}$. In Pd, the barrier does not depend on the step height. Barriers for climbing by exchange across the step edge are lower than those by hopping for all elements except Ag. Double exchange motions have the higher energy barrier than those of exchange or hopping. However, 
TABLE VII. Activation energy barriers $(\mathrm{eV})$ of horizontal diffusions to the step corners on (001) surface.

\begin{tabular}{|c|c|c|c|c|c|c|c|}
\hline $\begin{array}{l}\text { Step corner } \\
\text { directions }\end{array}$ & Mechanisms & $\mathrm{Ni}$ & $\mathrm{Cu}$ & $\mathrm{Pd}$ & $\mathrm{Ag}$ & $\mathrm{Pt}$ & $\mathrm{Au}$ \\
\hline \multirow{12}{*}{$\begin{array}{l}\text { To the }[110] \\
\text { step corner }\end{array}$} & Hopping from & 0.429 & 0.527 & 0.746 & 0.520 & 1.102 & 0.652 \\
\hline & & $(0.786)$ & $(0.827)$ & $(0.978)$ & $(0.736)$ & (1.374) & $(0.784)$ \\
\hline & Exchange & 1.201 & 0.725 & 0.779 & 0.652 & 0.919 & 0.476 \\
\hline & & (1.558) & (1.026) & (1.012) & $(0.868)$ & (1.191) & (0.609) \\
\hline & Hopping from & 0.120 & 0.225 & 0.454 & 0.292 & 0.701 & 0.454 \\
\hline & & $(0.708)$ & $(0.801)$ & $(0.926)$ & $(0.723)$ & (1.254) & $(0.926)$ \\
\hline & Hopping from & 0.242 & 0.426 & 0.599 & 0.444 & 0.845 & 0.529 \\
\hline & & $(0.963)$ & (1.043) & (1.074) & $(0.887)$ & (1.392) & $(0.791)$ \\
\hline & Exchange & 0.890 & 0.643 & 0.772 & 0.622 & 0.918 & 0.478 \\
\hline & & (1.611) & (1.260) & (1.247) & $(1.065)$ & (1.466) & $(0.740)$ \\
\hline & Hopping from & 0.193 & 0.237 & 0.340 & 0.246 & 0.496 & 0.318 \\
\hline & & $(0.411)$ & (0.499) & $(0.584)$ & $(0.458)$ & $(0.801)$ & $(0.480)$ \\
\hline \multirow{12}{*}{$\begin{array}{l}\text { To the }[100] \\
\text { step corner }\end{array}$} & Hopping from & 0.610 & 0.771 & 1.001 & 0.761 & 1.398 & 0.804 \\
\hline & & $(0.704)$ & $(0.804)$ & (0.988) & $(0.764)$ & (1.365) & $(0.776)$ \\
\hline & Exchange & 1.265 & 0.873 & 0.945 & 0.782 & 1.161 & 0.616 \\
\hline & & (1.358) & (0.906) & $(0.932)$ & $(0.786)$ & (1.128) & $(0.588)$ \\
\hline & Hopping from & 0.122 & 0.228 & 0.453 & 0.291 & 0.703 & 0.456 \\
\hline & & $(0.684)$ & $(0.802)$ & $(0.925)$ & $(0.722)$ & $(1.256)$ & $(0.925)$ \\
\hline & Hopping from & 0.269 & 0.435 & 0.600 & 0.447 & 0.851 & 0.529 \\
\hline & & (1.008) & $(1.051)$ & (1.074) & (0.889) & (1.398) & $(0.791)$ \\
\hline & Exchange & 0.886 & 0.626 & 0.772 & 0.614 & 0.926 & 0.493 \\
\hline & & (1.625) & (1.241) & $(1.245)$ & $(1.056)$ & $(1.472)$ & $(0.754)$ \\
\hline & Hopping from & 0.138 & 0.209 & 0.345 & 0.239 & 0.518 & 0.336 \\
\hline & & $(0.470)$ & $(0.508)$ & $(0.580)$ & $(0.456)$ & (0.794) & $(0.472)$ \\
\hline
\end{tabular}

$\mathrm{Au}$ is an exceptional case, for which a double-exchange mechanism occurs more frequently than other mechanisms.

In diffusions along the two-layer-height [100] step, exchange has slightly higher barriers than those along the single-layer step regardless of elements. When the adatom hops along the [100] step, the barriers increase a little for $\mathrm{Ni}$, $\mathrm{Cu}$, and $\mathrm{Pd}$ and are nearly the same as those along the singlelayer step for $\mathrm{Ag}$ and $\mathrm{Au}$.

\section{Across the step edges}

In the descending diffusion across the double-layer [110] step, the exchange mechanism has the lowest barriers for $\mathrm{Ni}$,
$\mathrm{Cu}, \mathrm{Pd}$, and $\mathrm{Pt}$. On the other hand, the hopping and the double-exchange are energetically more favorable for Ag and $\mathrm{Au}$, respectively, as given in Table IV. The ES barriers for the two-layer-height step significantly increase from those of the one-layer-height step, regardless of elements and diffusion mechanisms. For $\mathrm{Cu}$, the ES barrier of exchange movement across the steps increases from $0.08 \mathrm{eV}$ of the onelayer step to $0.20 \mathrm{eV}$ of the two-layer step. Au has the highest $\mathrm{ES}$ barrier and $\mathrm{Cu}$ has the lowest one. In the diffusion across the two-layer-height [100] step, the descending motion by exchange has the zero value of ES barriers for all elements except for Ni. This means that adatom more frequently descends to the step edge rather than diffuses on the 


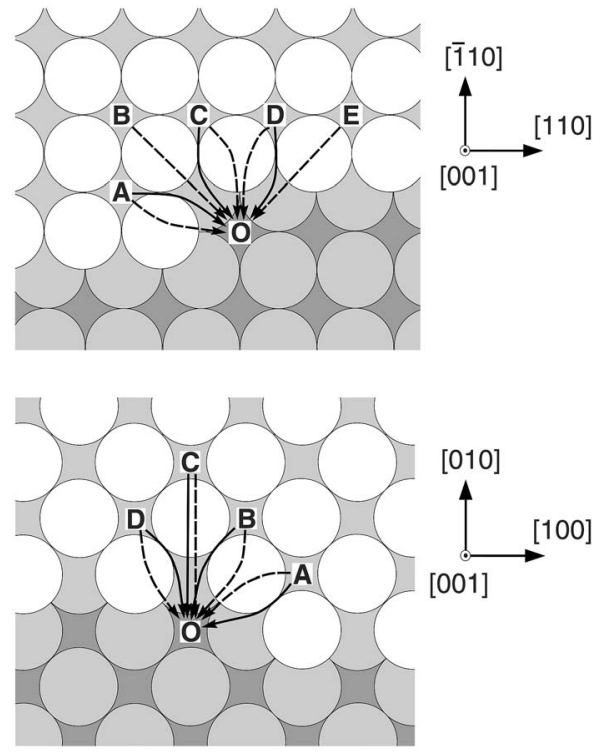

FIG. 10. Descending diffusion directions to the step corners on the (001) surface. Diffusion to the [110] step corner (top) and diffusion to the [100] step corner (bottom).

island. It is in good agreement with the result of the onelayer step. The ES barriers of the hopping are nonzero, and the double-exchange has higher barriers than hopping for all elements except for $\mathrm{Au}$.

\section{B. Steps on (111) surfaces}

Double-layer steps of $A$ type and $B$ type are modeled as displayed in Fig. 7. 42 atoms make the island, and a total of 330 atoms are used for the full models. The solid, dotted, and double-dotted arrows in Fig. 7 indicate the hopping, the exchange, and the double-exchange processes, respectively. In addition to the hopping along the step, we simulate three across-the-step diffusion mechanisms of which the final configurations are all the same for $A$ type, but not for $B$ type, as shown in Fig. 7.

In the $A$-type step case, the first across-the-step mechanism is the exchange mechanism where the original adatom pushes one of the upper-layer atoms up to the final position. The second mechanism considered is the double-exchange process in which the original adatom replaces one of the lower-layer atoms and then the lower-layer atom pushes one of the upper layer ones up to the final position. The third across-the-step mechanism considered is the hopping process where the original adatom hops up over the two layers at once. These routes are sketched in Fig. 7.

Similarly, three across mechanisms are considered in the case of the $B$-type step, as well as the hopping along the step. They are the exchange, the double-exchange, and the crosshopping mechanisms. The final configurations of the exchange and cross-hopping mechanisms coincide, while the double-exchange has a different final configuration, as illustrated also in Fig. 7. All the computed activation energy barriers are presented in Table $\mathrm{V}$ and are summarized as follows.

\section{Along the step edges}

In the hopping processes along the double-layer $A$-type step, the barriers slightly increase for $\mathrm{Ni}$ and decrease for $\mathrm{Pd}$, $\mathrm{Ag}, \mathrm{Pt}$, and $\mathrm{Au}$, compared with the cases of one-layer A-type steps. No change in the energy barrier of $\mathrm{Cu}$ is observed. However, with the hopping energy barriers along the $B$-type step, the values become slightly higher than those of the single-layer $B$-type steps for all species except $\mathrm{Ni}$.

\section{Across the step edges}

The vertical exchange mechanism reveals the same order of barrier heights, compared with that of the vertical hopping mechanism for each step edge. The barriers of exchange across the A-type step are slightly higher than those of hopping for $\mathrm{Pd}$ and $\mathrm{Ag}$, and somewhat lower for $\mathrm{Cu}$ and $\mathrm{Au}$, while the cases of $\mathrm{Ni}$ and $\mathrm{Pt}$ result in almost the same values for two different processes. This trend also applies to the corresponding descending mechanisms. The barriers of exchange across the $B$-type step are slightly higher than those of hopping for $\mathrm{Pd}, \mathrm{Pt}$, and $\mathrm{Au}$, and lower for $\mathrm{Cu}$ and $\mathrm{Ag}$. The double-exchange mechanism has the higher energy barriers than the hopping and exchange processes for both cases of $A$-type and $B$-type steps, except for Ni. The double-exchange barrier of $\mathrm{Ni}$ is much lower than its hopping barrier.

\section{Steps on (110) surfaces}

Double-layer [110] and [001] steps are placed on the (110) surface, as given in Fig. 8. 49 and 54 atoms are employed to model the islands, and thus 343 and 342 atoms are used for the full models of $[1 \overline{1} 0]$ and [001] steps, respectively. The solid and dotted arrows in Fig. 8 indicate the hopping and the exchange processes, as previously denoted. We conduct simulations of one hopping move along the step and a hopping and an exchange process across both of the step types, as depicted in Fig. 8. The calculated activation energy barriers are presented in Table VI.

\section{Along the step edges}

The barriers for in-channel hopping along the edge of the double-layer [1 $1 \overline{1} 0]$ step are nearly the same as those of the corresponding cases of the single-layer step. However, the barriers for out-channel hopping along the double-layer [001] step are lower than those along the single-layer step for all species. For example, the energy barrier for $\mathrm{Cu}$ decreases from $0.83 \mathrm{eV}$ of the single-layer case to $0.74 \mathrm{eV}$ of the double-layer case, both for out-channel hopping along the [001] step direction. 
TABLE VIII. Activation energy barriers $(\mathrm{eV})$ of descending diffusions to the [110] step corner on the (001) surface.

\begin{tabular}{|c|c|c|c|c|c|c|c|}
\hline $\begin{array}{l}\text { Step corner } \\
\text { directions }\end{array}$ & Mechanisms & $\mathrm{Ni}$ & $\mathrm{Cu}$ & $\mathrm{Pd}$ & $\mathrm{Ag}$ & $\mathrm{Pt}$ & $\mathrm{Au}$ \\
\hline \multirow[t]{24}{*}{$\begin{array}{l}\text { To the }[110] \\
\text { step corner }\end{array}$} & $\begin{array}{l}\text { Hopping } \\
\text { from A }\end{array}$ & 0.469 & 0.560 & 0.665 & 0.519 & 0.921 & 0.561 \\
\hline & & $(1.442)$ & (1.191) & (1.112) & $(0.948)$ & (1.435) & $(0.807)$ \\
\hline & & 0.093 & 0.083 & 0.044 & 0.052 & 0.119 & 0.173 \\
\hline & $\begin{array}{l}\text { Exchange } \\
\text { from A }\end{array}$ & 0.349 & 0.346 & 0.455 & 0.349 & 0.605 & 0.361 \\
\hline & & $(1.322)$ & $(0.977)$ & $(0.902)$ & $(0.778)$ & (1.119) & $(0.607)$ \\
\hline & & 0.000 & 0.000 & 0.000 & 0.000 & 0.000 & 0.000 \\
\hline & $\begin{array}{l}\text { Exchange } \\
\text { from B }\end{array}$ & 0.913 & 0.906 & 0.887 & 0.770 & 1.018 & 0.517 \\
\hline & & $(1.731)$ & $(1.531)$ & $(1.365)$ & (1.217) & $(1.571)$ & $(0.782)$ \\
\hline & & 0.537 & 0.429 & 0.266 & 0.303 & 0.216 & 0.129 \\
\hline & $\begin{array}{l}\text { Hopping } \\
\text { from C }\end{array}$ & 0.521 & 0.545 & 0.655 & 0.508 & 0.911 & 0.557 \\
\hline & & (1.383) & (1.170) & (1.120) & (0.948) & $(1.447)$ & $(0.813)$ \\
\hline & & 0.145 & 0.068 & 0.034 & 0.041 & 0.109 & 0.169 \\
\hline & $\begin{array}{l}\text { Exchange } \\
\text { from C }\end{array}$ & 0.381 & 0.414 & 0.577 & 0.441 & 0.756 & 0.453 \\
\hline & & (1.243) & (1.038) & $(1.042)$ & $(0.880)$ & $(1.291)$ & $(0.709)$ \\
\hline & & 0.005 & 0.000 & 0.000 & 0.000 & 0.000 & 0.065 \\
\hline & $\begin{array}{l}\text { Hopping } \\
\text { from D }\end{array}$ & 0.683 & 0.712 & 0.728 & 0.596 & 0.986 & 0.591 \\
\hline & & (1.593) & (1.337) & (1.184) & (1.029) & $(1.512)$ & $(0.845)$ \\
\hline & & 0.307 & 0.235 & 0.107 & 0.129 & 0.184 & 0.203 \\
\hline & $\begin{array}{l}\text { Exchange } \\
\text { from D }\end{array}$ & 0.366 & 0.369 & 0.494 & 0.381 & 0.632 & 0.358 \\
\hline & & (1.276) & $(0.995)$ & $(0.950)$ & $(0.814)$ & (1.158) & $(0.612)$ \\
\hline & & 0.000 & 0.000 & 0.000 & 0.000 & 0.000 & 0.000 \\
\hline & $\begin{array}{l}\text { Exchange } \\
\text { from E }\end{array}$ & 0.508 & 0.562 & 0.722 & 0.562 & 0.928 & 0.532 \\
\hline & & $(1.431)$ & (1.190) & (1.179) & (0.996) & (1.456) & $(0.788)$ \\
\hline & & 0.132 & 0.085 & 0.101 & 0.095 & 0.126 & 0.144 \\
\hline
\end{tabular}

\section{Across the step edges}

In the diffusion across the step edges, the exchange mechanism is energetically more favorable than the hopping mechanism for all atomic elements except $\mathrm{Ni}$, which has a slightly higher value $(0.01 \mathrm{eV})$ of exchange barrier compared with the hopping barrier. In general, the energy barriers to climb over the double-layer steps are much higher than those of single-layer steps for all species. These barrier increases are greater in the hopping mechanism than in the exchange mechanism for $\mathrm{Pt}$ and $\mathrm{Au}$. It is of note that $\mathrm{Ni}$ or $\mathrm{Ag}$ has the lowest values of the ES barriers in all cases in Table VI.

\section{STEP CORNERS ON (001) SURFACES}

In this and the following two sections, our ADMD simulation is devoted to the diffusion mechanism in the vicinity of step corner on the fcc metal substrates of the three surface orientations and the six atomic species which have been used throughout the paper. The step-corner diffusion is of particular interest due to the kink Ehrlich-Schwoebel (KES) barrier in relation to island growth and surface morphology. ${ }^{5,17-20}$ Among the examples, the KES effect has been observed on the $\mathrm{Cu}\left(\begin{array}{lll}1 & 1 & 17\end{array}\right)$ surface by variable temperature scanning tunneling microscopy which was unable to be explained by the Bales-Zangwill instability. ${ }^{21}$ Some studies have also shown that the morphological instability of steps are driven by the KES effect, rather than by the ES effect. ${ }^{18,19}$

We first present the results on (001) surfaces in this section. The other two surfaces, (111) and (110), will be dealt with in the next two sections, respectively. In each substrate case, horizontal and descending diffusive paths into the corner position are considered, as shown in the corresponding figures. 
TABLE IX. Activation energy barriers (eV) of descending diffusions to the [100] step corner on the (001) surface.

\begin{tabular}{|c|c|c|c|c|c|c|c|}
\hline $\begin{array}{l}\text { Step corner } \\
\text { directions }\end{array}$ & Mechanisms & $\mathrm{Ni}$ & $\mathrm{Cu}$ & $\mathrm{Pd}$ & $\mathrm{Ag}$ & $\mathrm{Pt}$ & $\mathrm{Au}$ \\
\hline \multirow{24}{*}{$\begin{array}{l}\text { To the } \\
{[100]} \\
\text { step } \\
\text { corner }\end{array}$} & \multirow[t]{3}{*}{ Hopping from A } & 0.698 & 0.714 & 0.723 & 0.594 & 0.977 & 0.582 \\
\hline & & $(1.670)$ & (1.344) & (1.173) & (1.024) & $(1.498)$ & $(0.835)$ \\
\hline & & 0.322 & 0.237 & 0.102 & 0.127 & 0.175 & 0.194 \\
\hline & \multirow[t]{3}{*}{ Exchange from $\mathrm{A}$} & 0.358 & 0.374 & 0.501 & 0.387 & 0.640 & 0.361 \\
\hline & & $(1.329)$ & (1.004) & $(0.951)$ & $(0.817)$ & $(1.161)$ & $(0.615)$ \\
\hline & & 0.000 & 0.000 & 0.000 & 0.000 & 0.000 & 0.000 \\
\hline & \multirow[t]{3}{*}{ Hopping from B } & 0.525 & 0.551 & 0.655 & 0.509 & 0.911 & 0.558 \\
\hline & & $(1.401)$ & (1.179) & (1.126) & $(0.951)$ & $(1.458)$ & $(0.823)$ \\
\hline & & 0.149 & 0.074 & 0.034 & 0.042 & 0.109 & 0.170 \\
\hline & \multirow[t]{3}{*}{ Exchange from $\mathrm{B}$} & 0.372 & 0.389 & 0.579 & 0.425 & 0.770 & 0.449 \\
\hline & & (1.248) & (1.017) & $(1.050)$ & $(0.867)$ & $(1.317)$ & $(0.714)$ \\
\hline & & 0.000 & 0.000 & 0.000 & 0.000 & 0.000 & 0.061 \\
\hline & \multirow[t]{3}{*}{ Hopping from $\mathrm{C}$} & 0.574 & 0.563 & 0.646 & 0.520 & 0.908 & 0.704 \\
\hline & & $(1.401)$ & (1.190) & $(1.124)$ & $(0.967)$ & $(1.460)$ & $(0.945)$ \\
\hline & & 0.198 & 0.086 & 0.025 & 0.053 & 0.106 & 0.316 \\
\hline & \multirow[t]{3}{*}{ Exchange from $\mathrm{C}$} & 0.713 & 0.668 & 0.873 & 0.354 & 1.016 & 0.529 \\
\hline & & $(1.540)$ & $(1.295)$ & $(1.351)$ & $(1.183)$ & $(1.568)$ & $(0.793)$ \\
\hline & & 0.337 & 0.191 & 0.252 & 0.000 & 0.214 & 0.141 \\
\hline & \multirow[t]{3}{*}{ Hopping from D } & 0.512 & 0.560 & 0.655 & 0.512 & 0.906 & 0.551 \\
\hline & & $(1.433)$ & (1.189) & (1.111) & $(0.947)$ & $(1.432)$ & $(0.803)$ \\
\hline & & 0.136 & 0.083 & 0.034 & 0.045 & 0.104 & 0.163 \\
\hline & \multirow[t]{3}{*}{ Exchange from D } & 0.396 & 0.347 & 0.441 & 0.343 & 0.575 & 0.337 \\
\hline & & $(1.317)$ & $(0.977)$ & $(0.897)$ & $(0.777)$ & (1.101) & $(0.589)$ \\
\hline & & 0.020 & 0.000 & 0.000 & 0.000 & 0.000 & 0.000 \\
\hline
\end{tabular}

\section{A. Horizontal diffusions}

The first example is the horizontal diffusions of a single adatom from four different initial positions toward the corners of [110] and [100] steps on the (001) surface, as shown respectively in Fig. 9. Those four positions on the substrate are denoted by A to D, and the step corner, which corresponds to the final position, is identified by O. Solid and dotted arrows indicate the diffusion paths of hopping and exchange, respectively. Calculations of four hopping pathways and two exchange pathways are considered in each model of the step corner. For the [110] step corner, the substrate model employs six atomic layers of 64 atoms and the single-layer step consists of 28 atoms to locate the step corner in the middle, as given in Fig. 9. For the [100] step corner, six layers of 72 atoms constitute the (001) substrate and 33 atoms are used for the single-layer step, as shown also in Fig. 9. Therefore, a total of 412 and 465 atoms are involved for [110] and [100] step corner modelings, respectively.

The computed barriers for the presumed diffusion pathways are presented in Table VII, where two rows are assigned to every single mechanism. The values of the top row are the activation energy barriers of the paths to the step corner from the initial position, while the bottom-row num- bers in parentheses are the energy barriers of the reverse processes. The barriers for diffusion to the corner are considerably lower than those of the corresponding reverse processes (i.e., from the corner to different positions). It clearly demonstrates that the atoms tend to attach to the step corner rather than to depart from it.

In diffusions toward the [110] step corner, the hopping from position $\mathrm{B}$ reveals the lowest barrier for $\mathrm{Ni}$ and $\mathrm{Cu}$. On the other hand, for $\mathrm{Pd}, \mathrm{Ag}, \mathrm{Pt}$, and $\mathrm{Au}$, the hopping from position $\mathrm{D}$ has the lowest value. Especially, for $\mathrm{Pt}$, the barrier of hopping along the step (from D to O) is $0.20 \mathrm{eV}$ lower than that from position B. For all atoms, the barriers for hopping along the step to the step corner (from D to O) are equivalent to or slightly lower than those along the step edge without the corner. Hopping from position A has the higher barrier than that of other hopping paths because the atom next to the step corner hinders the movement of the adatom. The exchange has much higher barriers than the hopping for all elements except for Au.

When the [100] step corner is considered, the hopping from $\mathrm{D}$ has the lowest barrier for all atomic species except for Ni. As in the case of the previous [110] step corner, the barriers for hopping along the step toward the step corner (from A to $\mathrm{O}$ ) are equivalent to or slightly lower than those along the step edge without the corner. In horizontal diffu- 
sion to the [100] step corner (from $\mathrm{C}$ to $\mathrm{O}$ ), the exchange mechanism requires higher activation energy than the hopping mechanism, for all species but for Au.

\section{B. Descending diffusions}

The descending pathways of an adatom from several initial positions on the terrace down to the step corner are prescribed in Fig. 10. Five and four initial positions on the terrace, denoted by capital letters, are considered for [110] and [100] step corners, respectively. Three hopping and five exchange pathways are analyzed for the [110] step corner, and four hopping and four exchange pathways are employed for the [100] step corner. Solid and dotted arrows denote the routes of hopping and exchange mechanisms. The models employ 36 and 39 atoms for step corners, both of which are placed onto the (001) substrate of six atomic layers used in the previous subsection. Thus, the models consist of 420 and 471 atoms in total for [110] and [100] step corners, respectively.

The energy barriers for different descending pathways are presented in Table VIII for the [110] step corner and in Table IX for the [100] step corner. The values on the first, second, and third rows are the barriers for descending paths to the step corner, for their reverse processes, and the ES barriers, respectively. The ES barrier is calculated by subtracting the barrier of the flat-surface case from the first-row value, for each atom species, and it is set to zero when a negative value is obtained.

In descending processes to the [110] step corner, diffusions by the exchange from position A have the lowest barriers for all elements. Especially, some barriers of descending by exchange are lower than the lowest barriers of diffusions on the flat (100) surface. For $\mathrm{Cu}$, the barriers for descending processes by exchange from positions $\mathrm{A}, \mathrm{C}$, and $\mathrm{D}$ are 0.35 , 0.41 , and $0.37 \mathrm{eV}$, which are lower than the barrier for hopping on the flat surface, $0.48 \mathrm{eV}$. This implies that when a $\mathrm{Cu}$ adatom diffuses from position $\mathrm{A}, \mathrm{C}$, or $\mathrm{D}$ to the step corner, there is no ES barrier. Therefore, the $\mathrm{Cu}$ atom can move to the corner without any additional energy. Calculations for $\mathrm{Pd}$ and $\mathrm{Ag}$ show the same results as the $\mathrm{Cu}$ case. In $\mathrm{Au}$, all exchange moves have a lower barrier than any other hopping mechanisms. For $\mathrm{Au}$, the exchange mechanism is the dominant diffusion process not only on the flat surface but across the step edge and step corner. The ES barriers of exchange from $\mathrm{A}$ and $\mathrm{D}$ are zeros for all elements.

When a single adatom descends to the [100] step corner, exchange from position $\mathrm{D}$ has the lowest barrier for all atomic species except Ni. The positions from which descending has the highest barrier are all different from element to element. The hopping from position $\mathrm{A}$ has the highest barrier for $\mathrm{Cu}$ and $\mathrm{Ag}$, and the exchange from $\mathrm{C}$ has the highest for $\mathrm{Ni}, \mathrm{Pd}$, and Pt. In $\mathrm{Au}$, the hopping from position $\mathrm{C}$ needs the highest energy to overcome the barrier. Due to the presence of the atom next to the step corner, the exchange barriers from B are slightly higher than those from D, except Ni. However, the hoppings from B and D have nearly the same energy barrier. The ES barriers of exchange from A are zero for all elements.

\section{STEP CORNERS ON (111) SURFACES}

\section{A. Horizontal diffusions}

Diffusion paths of a single atom from five different positions to the $A$-type and $B$-type step corners on the (111) surface are shown in Fig. 11. The initial positions on the same atomic layer are denoted by A through E. Solid and dotted arrows illustrate the directions and pathways of hopping and exchange mechanisms, respectively. The models, except the diffusing atom, employ six atomic layers of 64 atoms with 28 atoms for step corners, and they thus consist of 412 atoms in total for both step corners.

The activation energy barriers for different pathways of diffusion are summarized in Table X. For each diffusion mechanism, the values on the top and bottom rows are the energy barriers for the paths to the step corner and those of the reverse process, respectively. The barriers for diffusion to the corner are considerably lower than their reverse processes. That is, the reverse diffusion process from the corner site to the initial positions is less probable as in the previous case of (001) surfaces.

In hopping diffusion to the $A$-type step corner, the path from $\mathrm{C}$ to $\mathrm{O}$ has the lowest barrier for all species, except $\mathrm{Au}$ for which the hopping from position A has a lower barrier than that from site $\mathrm{C}$. This implies that the atom next to the corner plays a different role in the case of Au. That is, the neighboring atom assists the diffusion process of Au adatom, but hinders those of other elements. The hopping along the step edge has a higher barrier than those for other hopping mechanisms for all elements as can be noticed from Table X. The barriers for hopping along the step edge to the step corner site (from $\mathrm{E}$ to $\mathrm{O}$ ) are slightly lower than those along the step edge without the corner. The barriers for exchange moves to the step corner are significantly reduced compared with those on the (111) flat surface due to the presence of step corner. We failed to obtain a stable state of the models
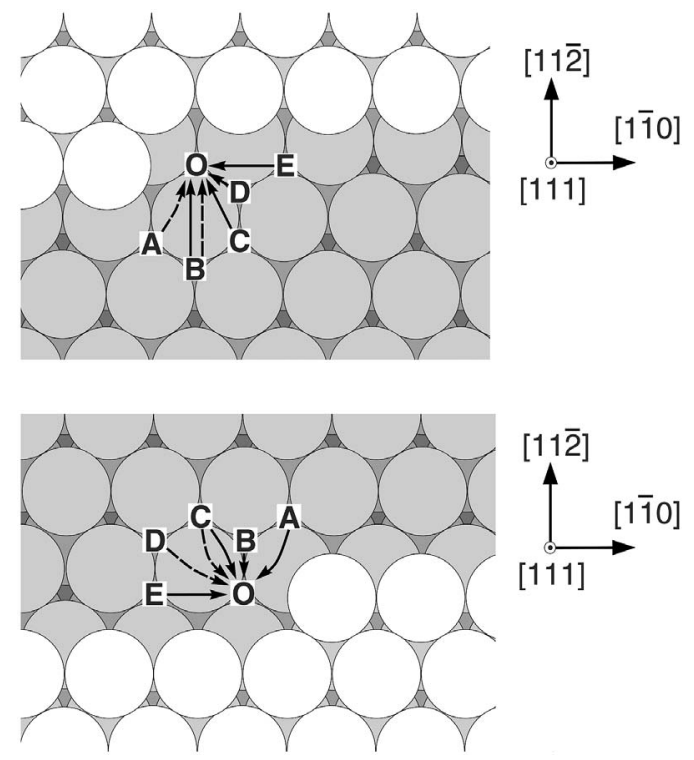

FIG. 11. Horizontal diffusion directions to the step corners on the (111) surface. Diffusion to the $A$-step corner (top) and diffusion to the $B$-step corner (bottom). 
TABLE X. Activation energy barriers (eV) of horizontal diffusions to the step corners on the (111) surface.

\begin{tabular}{|c|c|c|c|c|c|c|c|}
\hline $\begin{array}{l}\text { Step corner } \\
\text { directions }\end{array}$ & Mechanisms & $\mathrm{Ni}$ & $\mathrm{Cu}$ & $\mathrm{Pd}$ & $\mathrm{Ag}$ & $\mathrm{Pt}$ & $\mathrm{Au}$ \\
\hline \multirow{14}{*}{$\begin{array}{l}\text { To the } \\
A \text {-type } \\
\text { step } \\
\text { corner }\end{array}$} & \multirow[t]{2}{*}{ Hopping from A } & 0.181 & 0.087 & 0.125 & 0.098 & 0.129 & 0.056 \\
\hline & & $(0.713)$ & $(0.618)$ & $(0.630)$ & $(0.526)$ & $(0.778)$ & $(0.414)$ \\
\hline & \multirow[t]{2}{*}{ Hopping from B } & 0.181 & 0.088 & 0.068 & 0.029 & 0.128 & 0.097 \\
\hline & & $(0.713)$ & $(0.620)$ & $(0.872)$ & $(0.707)$ & (1.159) & $(0.663)$ \\
\hline & \multirow[t]{2}{*}{ Exchange from B } & 1.080 & 0.947 & 0.882 & 0.732 & 1.140 & 0.641 \\
\hline & & $(1.611)$ & (1.479) & $(1.686)$ & $(1.410)$ & $(2.171)$ & (1.208) \\
\hline & \multirow[t]{2}{*}{ Hopping from $\mathrm{C}$} & Model & 0.004 & 0.079 & 0.037 & 0.129 & 0.093 \\
\hline & & Fail & $(0.840)$ & $(0.887)$ & $(0.719)$ & $(1.166)$ & $(0.663)$ \\
\hline & \multirow[t]{2}{*}{ Exchange from $\mathrm{C}$} & Model & 0.806 & 0.901 & 0.765 & 1.156 & 0.649 \\
\hline & & Fail & (1.697) & (1.709) & $(1.448)$ & (2.193) & (1.219) \\
\hline & \multirow[t]{2}{*}{ Hopping from D } & Model & model & model & model & model & 0.016 \\
\hline & & Fail & fail & fail & fail & fail & $(0.469)$ \\
\hline & \multirow[t]{2}{*}{ Hopping from E } & 0.125 & 0.215 & 0.349 & 0.243 & 0.513 & 0.330 \\
\hline & & $(0.337)$ & $(0.474)$ & $(0.588)$ & $(0.451)$ & $(0.808)$ & $(0.484)$ \\
\hline \multirow{12}{*}{$\begin{array}{l}\text { To the } \\
B \text {-type } \\
\text { step } \\
\text { corner }\end{array}$} & \multirow[t]{2}{*}{ Hopping from A } & 0.000 & 0.020 & 0.140 & 0.072 & 0.237 & 0.170 \\
\hline & & $(0.649)$ & $(0.549)$ & $(0.649)$ & $(0.502)$ & $(0.895)$ & $(0.536)$ \\
\hline & \multirow[t]{2}{*}{ Hopping from B } & Model & model & model & model & model & model \\
\hline & & Fail & fail & fail & fail & fail & fail \\
\hline & \multirow[t]{2}{*}{ Hopping from $\mathrm{C}$} & Model & 0.064 & 0.089 & 0.043 & 0.147 & 0.106 \\
\hline & & Fail & $(0.841)$ & $(0.897)$ & $(0.726)$ & (1.183) & $(0.674)$ \\
\hline & \multirow[t]{2}{*}{ Exchange from $\mathrm{C}$} & Model & 0.778 & 0.892 & 0.757 & 1.142 & 0.636 \\
\hline & & Fail & $(1.613)$ & $(1.701)$ & $(1.440)$ & (2.177) & (1.204) \\
\hline & \multirow[t]{2}{*}{ Exchange from D } & 1.099 & 0.943 & 0.872 & 0.722 & 1.122 & 0.632 \\
\hline & & $(1.343)$ & (1.194) & $(1.667)$ & (1.383) & (2.144) & (1.195) \\
\hline & \multirow[t]{2}{*}{ Hopping from $\mathrm{E}$} & 0.321 & 0.283 & 0.377 & 0.297 & 0.466 & 0.245 \\
\hline & & $(0.565)$ & $(0.534)$ & $(0.613)$ & $(0.498)$ & $(0.770)$ & $(0.417)$ \\
\hline
\end{tabular}

for hopping from position $\mathrm{D}$ because the adatom moves to the corner during minimization due to the shallow depth of potential well on position D, except Au.

When an adatom diffuses to $B$-type step corner, the hopping from position $\mathrm{A}$ has an extremely low value of energy barrier for $\mathrm{Ni}$ and $\mathrm{Cu}$. However, the hopping from position $\mathrm{C}$ is more frequent than from position A for other elements. The barriers for hopping along the step to the step corner (from $\mathrm{E}$ to $\mathrm{O}$ ) are slightly lower than those along the step edge without the corner except for Au. Diffusion by exchange has much higher barriers than those by hopping for all cases.

\section{B. Descending diffusions}

The descending pathways of a single atom to the step corners on the (111) surface are depicted in Fig. 12. Seven different local minima on the terrace, denoted by A to $\mathrm{G}$, are considered respectively for $A$-type and $B$-type step corners. Five hopping and five exchange pathways, indicated respectively by solid and dotted arrows, are examined for both types of the step corner. The models, except the diffusing
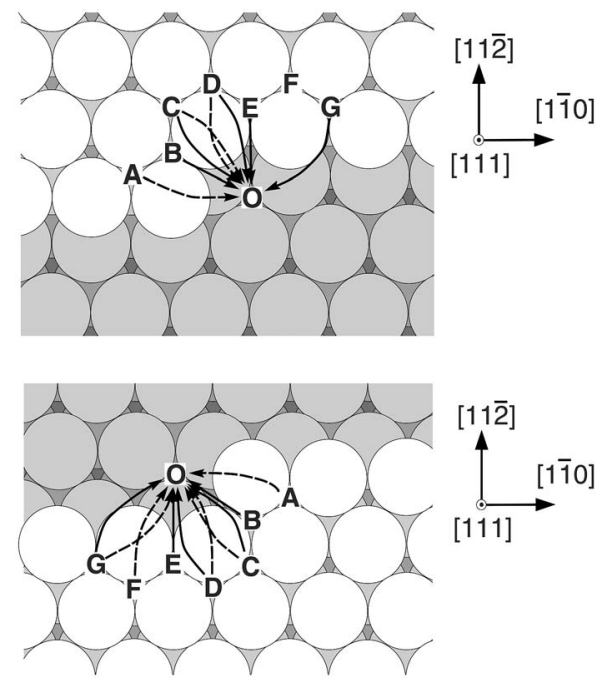

FIG. 12. Descending diffusion directions to the step corners on the (111) surface. Diffusion to the $A$-step corner (top) and diffusion to the $B$-step corner (bottom). 
TABLE XI. Activation energy barriers $(\mathrm{eV})$ of descending diffusions to the $A$-type step corner on the (001) surface.

\begin{tabular}{|c|c|c|c|c|c|c|c|}
\hline $\begin{array}{l}\text { Step corner } \\
\text { directions }\end{array}$ & Mechanisms & $\mathrm{Ni}$ & $\mathrm{Cu}$ & $\mathrm{Pd}$ & $\mathrm{Ag}$ & $\mathrm{Pt}$ & $\mathrm{Au}$ \\
\hline \multirow{30}{*}{$\begin{array}{l}\text { To the } \\
A \text {-type } \\
\text { step } \\
\text { corner }\end{array}$} & \multirow[t]{3}{*}{ Exchange from A } & 0.101 & 0.201 & 0.338 & 0.241 & 0.455 & 0.266 \\
\hline & & (1.359) & (1.124) & $(1.121)$ & $(0.932)$ & $(1.442)$ & $(0.800)$ \\
\hline & & 0.040 & 0.158 & 0.229 & 0.177 & 0.284 & 0.149 \\
\hline & \multirow[t]{3}{*}{ Hopping from $\mathrm{B}$} & 0.476 & 0.394 & 0.357 & 0.292 & 0.477 & 0.278 \\
\hline & & $(1.527)$ & (1.259) & (1.148) & $(0.984)$ & $(1.477)$ & $(0.822)$ \\
\hline & & 0.415 & 0.351 & 0.248 & 0.228 & 0.306 & 0.161 \\
\hline & \multirow[t]{3}{*}{ Hopping from $\mathrm{C}$} & 0.475 & 0.394 & 0.348 & 0.304 & 0.453 & 0.264 \\
\hline & & $(1.526)$ & $(1.259)$ & (1.149) & $(0.987)$ & $(1.482)$ & $(0.834)$ \\
\hline & & 0.414 & 0.351 & 0.239 & 0.240 & 0.282 & 0.147 \\
\hline & \multirow[t]{3}{*}{ Exchange from $\mathrm{C}$} & 0.538 & 0.277 & 0.374 & 0.293 & 0.440 & 0.235 \\
\hline & & (1.589) & $(1.142)$ & $(1.176)$ & $(0.975)$ & $(1.470)$ & $(0.805)$ \\
\hline & & 0.477 & 0.234 & 0.265 & 0.229 & 0.269 & 0.118 \\
\hline & \multirow[t]{3}{*}{ Hopping from D } & 0.447 & 0.385 & 0.359 & 0.307 & 0.474 & 0.282 \\
\hline & & $(1.486)$ & $(1.252)$ & $(1.162)$ & $(0.992)$ & $(1.501)$ & $(0.848)$ \\
\hline & & 0.386 & 0.342 & 0.250 & 0.243 & 0.303 & 0.165 \\
\hline & \multirow[t]{3}{*}{ Exchange from D } & 0.553 & 0.278 & 0.376 & 0.295 & 0.448 & 0.251 \\
\hline & & $(1.592)$ & $(1.146)$ & (1.179) & $(0.980)$ & $(1.476)$ & $(0.817)$ \\
\hline & & 0.492 & 0.235 & 0.267 & 0.231 & 0.277 & 0.134 \\
\hline & \multirow[t]{3}{*}{ Hopping from E } & 0.334 & 0.332 & 0.357 & 0.287 & 0.481 & 0.285 \\
\hline & & $(1.487)$ & $(1.251)$ & $(1.161)$ & $(0.989)$ & $(1.496)$ & $(0.834)$ \\
\hline & & 0.273 & 0.289 & 0.248 & 0.223 & 0.310 & 0.168 \\
\hline & \multirow[t]{3}{*}{ Exchange from $\mathrm{F}$} & 0.334 & 0.329 & 0.446 & 0.349 & 0.534 & 0.291 \\
\hline & & (1.419) & $(1.201)$ & $(1.238)$ & (1.029) & $(1.544)$ & $(0.845)$ \\
\hline & & 0.273 & 0.286 & 0.337 & 0.285 & 0.363 & 0.174 \\
\hline & \multirow[t]{3}{*}{ Hopping from $\mathrm{G}$} & 0.435 & 0.422 & 0.396 & 0.339 & 0.526 & 0.326 \\
\hline & & (1.634) & $(1.343)$ & (1.188) & $(1.035)$ & $(1.520)$ & $(0.862)$ \\
\hline & & 0.374 & 0.379 & 0.287 & 0.275 & 0.355 & 0.209 \\
\hline & \multirow[t]{3}{*}{ Exchange from $\mathrm{G}$} & 0.222 & 0.280 & 0.446 & 0.333 & 0.547 & 0.297 \\
\hline & & $(1.421)$ & (1.201) & $(1.237)$ & (1.029) & $(1.542)$ & $(0.833)$ \\
\hline & & 0.161 & 0.237 & 0.337 & 0.269 & 0.376 & 0.180 \\
\hline
\end{tabular}

atom, employ 36 atoms for the step corners onto the six-layer substrate used in the previous subsection, and thus total 420 atoms and a diffusing atom are considered.

The activation energy barriers for these diverse descending movements to the step corners on the (111) surface are given in Tables XI and XII, respectively, for $A$-type and $B$-type step corners. The values on the first, second, and third rows for each mechanism are, respectively, the descending barrier (i.e., from the initial site down to the corner), the reverse-process barrier (i.e., climbing from the corner), and the ES barrier.

In descending processes to the $A$-type step corner (Table $\mathrm{XI}$ ), diffusion by the exchange move from $\mathrm{A}$ has the lowest energy barriers for all elements except $\mathrm{Pt}$ and $\mathrm{Au}$. The exchange barrier for position $\mathrm{C}$ is the lowest for $\mathrm{Pt}$ and $\mathrm{Au}$. Hopping mechanisms reveal slightly higher than or nearly equivalent to exchange barriers, except for Ni. The variation of energy barriers for $\mathrm{Ni}$ is relatively larger than other spe- cies' cases. It requires only $0.10 \mathrm{eV}$ for hopping from A, while it requires $0.54 \mathrm{eV}$ for exchange from position $\mathrm{C}$. The difference in barriers between mechanisms is up to $0.44 \mathrm{eV}$ for $\mathrm{Ni}$, but just $0.02 \mathrm{eV}$ for $\mathrm{Pt}$.

When a single adatom diffuses to the $B$-type step corner (Table XII), the exchange from position $G$ has the lowest barrier for all elements except the Au case. These results significantly differ from the descending moves to the $A$-type step corner. The barrier for exchange from position $\mathrm{G}$ is considerably lower than those for the other descending processes, as given in Table XII. On the other hand, in the case of $\mathrm{Au}$, most descending processes have nearly the same energy barriers except the hopping diffusion from $\mathrm{G}$ to $\mathrm{O}$.

As can be noticed by comparing the routes of Fig. 12, the step directions and step corners of both types are equivalent to each other. However, the characteristics of diffusive movements to those corners are drastically different depending on the step type, which can easily confirm if we compare the 
TABLE XII. Activation energy barriers (eV) of descending diffusions to the $B$-type step corner on the (001) surface.

\begin{tabular}{|c|c|c|c|c|c|c|c|}
\hline $\begin{array}{l}\text { Step corner } \\
\text { directions }\end{array}$ & Mechanisms & $\mathrm{Ni}$ & $\mathrm{Cu}$ & $\mathrm{Pd}$ & $\mathrm{Ag}$ & $\mathrm{Pt}$ & $\mathrm{Au}$ \\
\hline \multirow{30}{*}{$\begin{array}{l}\text { To the } \\
B \text {-type } \\
\text { step } \\
\text { corner }\end{array}$} & \multirow[t]{3}{*}{ Exchange from A } & 0.519 & 0.376 & 0.417 & 0.329 & 0.500 & 0.258 \\
\hline & & (1.631) & (1.243) & $(1.200)$ & (1.019) & $(1.488)$ & $(0.795)$ \\
\hline & & 0.458 & 0.333 & 0.308 & 0.265 & 0.329 & 0.141 \\
\hline & \multirow[t]{3}{*}{ Hopping from $\mathrm{B}$} & 0.477 & 0.395 & 0.359 & 0.293 & 0.481 & 0.281 \\
\hline & & $(1.523)$ & $(1.260)$ & (1.149) & $(0.985)$ & $(1.479)$ & $(0.823)$ \\
\hline & & 0.416 & 0.352 & 0.250 & 0.229 & 0.310 & 0.164 \\
\hline & \multirow[t]{3}{*}{ Hopping from $\mathrm{C}$} & 0.476 & 0.395 & 0.348 & 0.305 & 0.454 & 0.266 \\
\hline & & $(1.522)$ & $(1.260)$ & $(1.151)$ & $(0.989)$ & $(1.484)$ & $(0.835)$ \\
\hline & & 0.415 & 0.352 & 0.239 & 0.241 & 0.283 & 0.149 \\
\hline & \multirow[t]{3}{*}{ Exchange from $\mathrm{C}$} & 0.238 & 0.271 & 0.375 & 0.294 & 0.460 & 0.260 \\
\hline & & $(1.285)$ & (1.136) & $(1.178)$ & $(0.977)$ & $(1.490)$ & $(0.829)$ \\
\hline & & 0.177 & 0.228 & 0.266 & 0.230 & 0.289 & 0.143 \\
\hline & \multirow[t]{3}{*}{ Hopping from D } & 0.437 & 0.379 & 0.359 & 0.305 & 0.476 & 0.284 \\
\hline & & $(1.478)$ & $(1.248)$ & $(1.160)$ & $(0.990)$ & $(1.501)$ & $(0.847)$ \\
\hline & & 0.376 & 0.336 & 0.250 & 0.241 & 0.305 & 0.167 \\
\hline & \multirow[t]{3}{*}{ Exchange from D } & 0.240 & 0.263 & 0.375 & 0.289 & 0.462 & 0.253 \\
\hline & & $(1.281)$ & (1.132) & (1.177) & $(0.974)$ & $(1.487)$ & $(0.817)$ \\
\hline & & 0.179 & 0.220 & 0.266 & 0.225 & 0.291 & 0.136 \\
\hline & \multirow[t]{3}{*}{ Hopping from E } & 0.330 & 0.329 & 0.354 & 0.284 & 0.478 & 0.282 \\
\hline & & $(1.477)$ & $(1.247)$ & (1.158) & $(0.986)$ & $(1.494)$ & $(0.834)$ \\
\hline & & 0.269 & 0.286 & 0.245 & 0.220 & 0.307 & 0.165 \\
\hline & \multirow[t]{3}{*}{ Exchange from $\mathrm{F}$} & 0.069 & 0.134 & 0.289 & 0.192 & 0.403 & 0.254 \\
\hline & & (1.154) & $(1.007)$ & $(1.081)$ & $(0.871)$ & $(1.415)$ & $(0.811)$ \\
\hline & & 0.008 & 0.091 & 0.180 & 0.128 & 0.232 & 0.137 \\
\hline & \multirow[t]{3}{*}{ Hopping from $\mathrm{G}$} & 0.426 & 0.423 & 0.395 & 0.338 & 0.523 & 0.327 \\
\hline & & (1.617) & $(1.343)$ & $(1.186)$ & (1.033) & $(1.521)$ & $(0.869)$ \\
\hline & & 0.365 & 0.380 & 0.286 & 0.274 & 0.352 & 0.210 \\
\hline & \multirow[t]{3}{*}{ Exchange from $\mathrm{G}$} & 0.008 & 0.086 & 0.288 & 0.177 & 0.419 & 0.287 \\
\hline & & $(1.200)$ & $(1.006)$ & $(1.080)$ & $(0.873)$ & $(1.417)$ & $(0.828)$ \\
\hline & & 0.000 & 0.043 & 0.179 & 0.113 & 0.248 & 0.170 \\
\hline
\end{tabular}

initial positions of the highest and lowest energy barriers for the two types.

\section{STEP CORNERS ON (110) SURFACES}

\section{A. Horizontal diffusion}

The horizontal diffusions of a single atom from four different positions (A-D) to the corners of [1 $\overline{1} 0]$ and [001] steps (denoted by $\mathrm{O}$ ) on the (110) surface are considered as shown in the top and bottom panels of Fig. 13, respectively. Solid and dotted arrows indicate the directions and pathways of the hopping and the exchange mechanism as in previous models. Seven atomic layers of 48 (56) atoms with 28 (24) atoms are employed for the model of the $[1 \overline{10}]$ ([001]) step edge. The obtained energy barriers for the specified diffusion mechanisms are presented in Table XIII. The values on the top and bottom rows are the barrier for diffusion to the step corner and that for the reverse process, respectively, for each diffusion path.

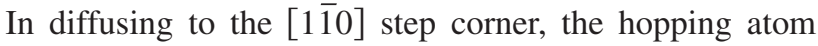
from position A experiences the lowest energy barrier for all atom types except $\mathrm{Au}$ of which the exchange barrier from $\mathrm{B}$ to $\mathrm{O}$ is slightly lower than that of $\mathrm{A}$ to $\mathrm{O}$. Due to the presence of step corner, the activation energy barriers for in-channel hopping along the $[1 \overline{10}]$ step to the corner site (hopping from position A) decrease somewhat in all cases of atomic species. The exchange mechanism has much lower barriers than hopping from the corresponding positions for all elements. Hopping from position $\mathrm{B}$ has the highest barrier for $\mathrm{Ni}, \mathrm{Pd}, \mathrm{Pt}$, and $\mathrm{Au}$, while for $\mathrm{Cu}$ and $\mathrm{Au}$, position $\mathrm{D}$ results in the highest diffusion barrier.

When an adatom diffuses to the [001] step corner, the hopping from position $\mathrm{C}$ has the lowest value of barrier for all atom types but $\mathrm{Ni}$, which agrees with the result of the hopping on the (110) flat surface. The barriers for the out- 

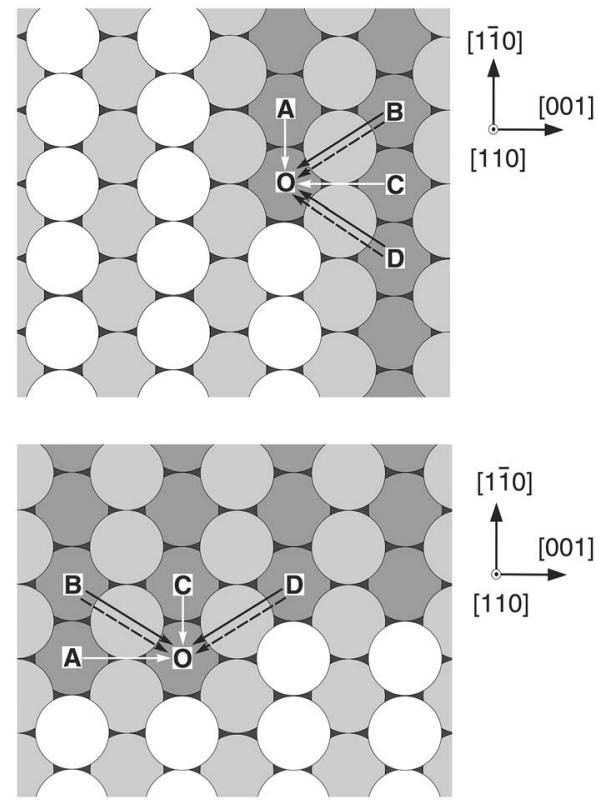

FIG. 13. Horizontal diffusion directions to the step corners on the (110) surface. Diffusion to the [1]10] step corner (top) and diffusion to the [001] step corner (bottom). channel hopping along the step to the step corner (from A) are nearly the same as those values along the step without the corner.

\section{B. Descending diffusions}

The descending pathways of a single atom to the [1]0] and [001] step corners on the (110) surface are illustrated in Fig. 14. Five (four) different initial positions on the terrace, denoted by A to E (A to D), are considered for the moves down to the $[1 \overline{1} 0]$ ([001]) step corner. Total eight pathways for both hopping and exchange mechanisms, as indicated respectively by solid and dotted arrows, are examined for both types of step corners. The same model as employed in the previous horizontal diffusion case is used for the [110] step corner, and seven atoms are added to the previous model for the one of the [001] step corner. The barriers for different pathways of descending to the step corners on (110) surface are presented in Tables XIV and XV. For each model, the first, second, and third rows are for the activation energy barriers of the descending moves to the step corner, their reverse processes, and the corresponding ES barriers, respectively, as in the previous cases.

TABLE XIII. Activation energy barriers (eV) of horizontal diffusions to the step corners on the (110) surface.

\begin{tabular}{|c|c|c|c|c|c|c|c|}
\hline $\begin{array}{l}\text { Step corner } \\
\text { directions }\end{array}$ & Mechanisms & $\mathrm{Ni}$ & $\mathrm{Cu}$ & $\mathrm{Pd}$ & $\mathrm{Ag}$ & $\mathrm{Pt}$ & $\mathrm{Au}$ \\
\hline \multirow{12}{*}{$\begin{array}{l}\text { To the } \\
{[1 \overline{1} 0]} \\
\text { step } \\
\text { corner }\end{array}$} & \multirow[t]{2}{*}{ Hopping from A } & 0.275 & 0.237 & 0.390 & 0.279 & 0.505 & 0.285 \\
\hline & & $(0.504)$ & $(0.488)$ & $(0.625)$ & $(0.481)$ & $(0.806)$ & $(0.451)$ \\
\hline & \multirow[t]{2}{*}{ Hopping from B } & 0.988 & 0.895 & 0.935 & 0.772 & 1.229 & 0.701 \\
\hline & & $(1.417)$ & $(1.185)$ & (1.140) & $(0.968)$ & $(1.474)$ & $(0.830)$ \\
\hline & \multirow[t]{2}{*}{ Exchange from $\mathrm{B}$} & 0.231 & 0.314 & 0.560 & 0.390 & 0.796 & 0.485 \\
\hline & & $(0.660)$ & $(0.603)$ & $(0.766)$ & $(0.586)$ & (1.041) & $(0.614)$ \\
\hline & \multirow[t]{2}{*}{ Hopping from $\mathrm{C}$} & 0.844 & 0.893 & 0.917 & 0.757 & 1.199 & 0.676 \\
\hline & & (1.232) & (1.182) & (1.136) & $(0.960)$ & (1.467) & $(0.820)$ \\
\hline & \multirow[t]{2}{*}{ Hopping from D } & 0.943 & 0.980 & 0.923 & 0.788 & 1.199 & 0.680 \\
\hline & & $(1.235)$ & (1.234) & (1.147) & $(0.984)$ & (1.483) & $(0.836)$ \\
\hline & \multirow[t]{2}{*}{ Exchange from D } & 0.586 & 0.518 & 0.639 & 0.507 & 0.807 & 0.447 \\
\hline & & $(0.872)$ & $(0.772)$ & $(0.864)$ & $(0.703)$ & (1.091) & $(0.603)$ \\
\hline \multirow{12}{*}{$\begin{array}{l}\text { To the } \\
{[001]} \\
\text { step } \\
\text { corner }\end{array}$} & \multirow[t]{2}{*}{ Hopping from A } & 0.813 & 0.822 & 0.995 & 0.757 & 1.413 & 0.821 \\
\hline & & $(0.907)$ & $(0.860)$ & $(0.986)$ & $(0.763)$ & (1.387) & (0.798) \\
\hline & \multirow[t]{2}{*}{ Hopping from B } & 0.500 & 0.570 & 0.812 & 0.597 & 1.156 & 0.689 \\
\hline & & $(0.912)$ & $(0.858)$ & (1.015) & $(0.791)$ & (1.397) & $(0.812)$ \\
\hline & \multirow[t]{2}{*}{ Exchange from B } & 0.212 & 0.292 & 0.546 & 0.379 & 0.778 & 0.480 \\
\hline & & $(0.625)$ & $(0.580)$ & $(0.749)$ & $(0.574)$ & (1.019) & $(0.604)$ \\
\hline & \multirow[t]{2}{*}{ Hopping from $\mathrm{C}$} & 0.216 & 0.207 & 0.364 & 0.260 & 0.468 & 0.260 \\
\hline & & $(0.589)$ & $(0.494)$ & $(0.582)$ & $(0.463)$ & $(0.731)$ & $(0.399)$ \\
\hline & \multirow[t]{2}{*}{ Hopping from D } & 1.077 & 1.184 & 1.163 & 0.979 & 1.516 & 0.862 \\
\hline & & (1.219) & $(1.222)$ & (1.145) & $(0.981)$ & (1.477) & $(0.832)$ \\
\hline & \multirow[t]{2}{*}{ Exchange from D } & 0.808 & 0.703 & 0.857 & 0.678 & 1.103 & 0.620 \\
\hline & & $(0.950)$ & $(0.742)$ & $(0.839)$ & $(0.679)$ & (1.064) & (0.590) \\
\hline
\end{tabular}




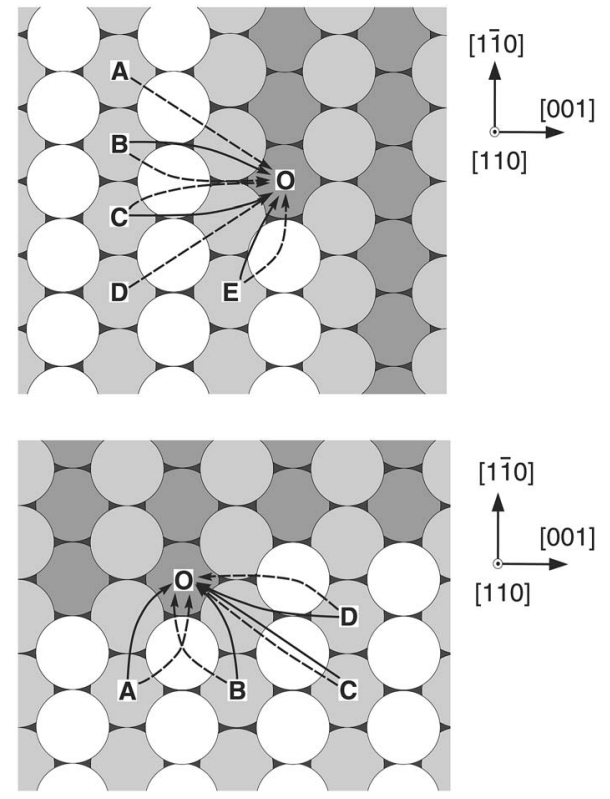

FIG. 14. Descending diffusion directions to the step corners on the (110) surface. Diffusion to the [1-10] step corner (top) and diffusion to the [001] step corner (bottom).
In descending processes to the [1]0] step corner, the hopping from $\mathrm{E}$ to $\mathrm{O}$ has the lowest barriers regardless of the atomic species, except $\mathrm{Ni}$ of which the lowest barrier is observed in the exchange move from the same position, E. It is noted that hopping from position $\mathrm{E}$ is a type of in-channel hopping. For descending diffusions from $\mathrm{B}$ and $\mathrm{C}$, the exchange path has much lower barrier than hopping, which is a type of out-channel hopping.

When a single adatom descends to the [001] step corner, there exist two pathways of in-channel hopping (i.e., from A and from B). The hopping has always the lowest barrier when it begins from position B no matter which atom type is considered. Therefore, the atom next to the corner assists hopping from $\mathrm{B}$ and, consequently, reduces the activation energy barrier. The highest barriers are obtained in hopping diffusion from position $\mathrm{C}$ or $\mathrm{D}$ depending on the element considered. These results are in agreement with the other diffusion processes on the (110) surface and clearly demonstrate the anisotropic characteristics of the surface.

\section{CONCLUDING REMARKS}

Action-derived molecular dynamics has been applied to the modeling and simulation of diffusion processes on flat

TABLE XIV. Activation energy barriers $(\mathrm{eV})$ of descending diffusions to the [1]0] step corner on the (110) surface.

\begin{tabular}{|c|c|c|c|c|c|c|c|}
\hline $\begin{array}{l}\text { Step corner } \\
\text { directions }\end{array}$ & Mechanisms & $\mathrm{Ni}$ & $\mathrm{Cu}$ & $\mathrm{Pd}$ & $\mathrm{Ag}$ & $\mathrm{Pt}$ & $\mathrm{Au}$ \\
\hline \multirow{24}{*}{$\begin{array}{l}\text { To the } \\
{[1 \overline{1} 0]} \\
\text { step } \\
\text { corner }\end{array}$} & \multirow[t]{3}{*}{ Exchange from $\mathrm{A}$} & 0.588 & 0.692 & 0.873 & 0.678 & 1.192 & 0.724 \\
\hline & & $(1.091)$ & $(0.983)$ & $(1.082)$ & $(0.874)$ & $(1.447)$ & $(0.861)$ \\
\hline & & 0.287 & 0.451 & 0.493 & 0.401 & 0.702 & 0.450 \\
\hline & \multirow[t]{3}{*}{ Hopping from B } & 1.133 & 1.053 & 0.979 & 0.839 & 1.271 & 0.730 \\
\hline & & (1.634) & $(1.345)$ & (1.188) & $(1.035)$ & $(1.525)$ & $(0.867)$ \\
\hline & & 0.832 & 0.812 & 0.599 & 0.562 & 0.781 & 0.456 \\
\hline & \multirow[t]{3}{*}{ Exchange from $\mathrm{B}$} & 0.490 & 0.588 & 0.821 & 0.610 & 1.115 & 0.660 \\
\hline & & $(0.991)$ & $(0.880)$ & $(1.030)$ & $(0.806)$ & $(1.369)$ & $(0.797)$ \\
\hline & & 0.189 & 0.347 & 0.441 & 0.333 & 0.625 & 0.386 \\
\hline & \multirow[t]{3}{*}{ Hopping from $\mathrm{C}$} & 1.074 & 1.033 & 0.974 & 0.833 & 1.264 & 0.726 \\
\hline & & $(1.558)$ & $(1.325)$ & $(1.182)$ & $(1.029)$ & $(1.514)$ & $(0.860)$ \\
\hline & & 0.773 & 0.792 & 0.594 & 0.556 & 0.774 & 0.452 \\
\hline & \multirow[t]{3}{*}{ Exchange from $\mathrm{C}$} & 0.509 & 0.588 & 0.825 & 0.611 & 1.132 & 0.673 \\
\hline & & $(0.993)$ & $(0.879)$ & $(1.033)$ & $(0.807)$ & $(1.382)$ & $(0.806)$ \\
\hline & & 0.208 & 0.347 & 0.445 & 0.334 & 0.642 & 0.399 \\
\hline & \multirow[t]{3}{*}{ Exchange from D } & 0.535 & 0.412 & 0.584 & 0.443 & 0.823 & 0.517 \\
\hline & & $(1.001)$ & $(0.704)$ & $(0.789)$ & $(0.639)$ & $(1.068)$ & $(0.645)$ \\
\hline & & 0.234 & 0.171 & 0.204 & 0.166 & 0.333 & 0.243 \\
\hline & \multirow[t]{3}{*}{ Hopping from D } & 0.440 & 0.361 & 0.418 & 0.336 & 0.608 & 0.412 \\
\hline & & $(0.983)$ & $(0.651)$ & $(0.618)$ & $(0.526)$ & $(0.851)$ & $(0.543)$ \\
\hline & & 0.139 & 0.120 & 0.038 & 0.059 & 0.118 & 0.138 \\
\hline & \multirow[t]{3}{*}{ Exchange from $\mathrm{E}$} & 0.411 & 0.459 & 0.701 & 0.513 & 0.930 & 0.536 \\
\hline & & $(0.953)$ & $(0.749)$ & $(0.901)$ & $(0.703)$ & (1.174) & $(0.666)$ \\
\hline & & 0.110 & 0.218 & 0.321 & 0.236 & 0.440 & 0.262 \\
\hline
\end{tabular}


TABLE XV. Activation energy barriers (eV) of descending diffusions to the [001] step corner on the (110) surface.

\begin{tabular}{|c|c|c|c|c|c|c|c|}
\hline $\begin{array}{l}\text { Step corner } \\
\text { directions }\end{array}$ & Mechanisms & $\mathrm{Ni}$ & $\mathrm{Cu}$ & $\mathrm{Pd}$ & $\mathrm{Ag}$ & $\mathrm{Pt}$ & $\mathrm{Au}$ \\
\hline \multirow{24}{*}{$\begin{array}{l}\text { To the } \\
{[001]} \\
\text { step } \\
\text { corner }\end{array}$} & \multirow[t]{3}{*}{ Hopping from A } & 0.597 & 0.590 & 0.787 & 0.598 & 1.099 & 0.649 \\
\hline & & $(1.145)$ & $(0.879)$ & $(0.973)$ & $(0.781)$ & $(1.316)$ & $(0.759)$ \\
\hline & & 0.296 & 0.349 & 0.407 & 0.321 & 0.609 & 0.375 \\
\hline & \multirow[t]{3}{*}{ Exchange from $\mathrm{A}$} & 0.509 & 0.500 & 0.705 & 0.526 & 0.931 & 0.538 \\
\hline & & (1.057) & $(0.789)$ & $(0.891)$ & $(0.710)$ & $(1.148)$ & $(0.648)$ \\
\hline & & 0.208 & 0.259 & 0.325 & 0.249 & 0.441 & 0.264 \\
\hline & \multirow[t]{3}{*}{ Hopping from B } & 0.454 & 0.330 & 0.410 & 0.319 & 0.596 & 0.394 \\
\hline & & $(0.962)$ & $(0.619)$ & $(0.609)$ & $(0.511)$ & $(0.833)$ & $(0.516)$ \\
\hline & & 0.153 & 0.089 & 0.030 & 0.042 & 0.106 & 0.120 \\
\hline & \multirow[t]{3}{*}{ Exchange from B } & 0.409 & 0.481 & 0.694 & 0.516 & 0.916 & 0.529 \\
\hline & & $(0.998)$ & $(0.771)$ & $(0.893)$ & $(0.708)$ & $(1.152)$ & $(0.652)$ \\
\hline & & 0.189 & 0.240 & 0.314 & 0.239 & 0.426 & 0.255 \\
\hline & \multirow[t]{3}{*}{ Hopping from $\mathrm{C}$} & 1.038 & 1.045 & 0.968 & 0.832 & 1.962 & 0.730 \\
\hline & & $(1.507)$ & $(1.335)$ & $(1.180)$ & $(1.031)$ & $(2.218)$ & $(0.864)$ \\
\hline & & 0.737 & 0.804 & 0.588 & 0.555 & 1.472 & 0.456 \\
\hline & \multirow[t]{3}{*}{ Exchange from $\mathrm{C}$} & 0.535 & 0.363 & 0.514 & 0.386 & 0.738 & 0.481 \\
\hline & & $(1.002)$ & $(0.652)$ & $(0.726)$ & $(0.585)$ & $(0.993)$ & $(0.616)$ \\
\hline & & 0.234 & 0.122 & 0.134 & 0.109 & 0.248 & 0.207 \\
\hline & \multirow[t]{3}{*}{ Hopping from D } & 1.066 & 1.045 & 0.983 & 0.841 & 1.282 & 0.766 \\
\hline & & $(1.634)$ & (1.333) & $(1.171)$ & $(1.025)$ & $(1.508)$ & $(0.885)$ \\
\hline & & 0.765 & 0.804 & 0.603 & 0.564 & 0.792 & 0.492 \\
\hline & \multirow[t]{3}{*}{ Exchange from D } & 0.685 & 0.726 & 0.845 & 0.660 & 1.161 & 0.754 \\
\hline & & $(1.253)$ & (1.014) & (1.034) & $(0.844)$ & (1.387) & $(0.873)$ \\
\hline & & 0.384 & 0.485 & 0.465 & 0.383 & 0.671 & 0.480 \\
\hline
\end{tabular}

fcc metal surfaces. In the companion paper (Paper I), basic diffusive moves of single adatom, as well as more complex situations such as multiple adatom's collective motion, have been analyzed by the method. In this paper we have simulated a diffusion mechanism associated with surface steps and kinks, such as exchanges through double layers and jumps over step corners. Various diffusion processes have been investigated to find the minimum-energy paths on the potential energy surface. In particular, the method is effective in simulating route-specific complex diffusion processes that are otherwise very difficult to simulate by conventional molecular dynamics. We have verified that some results are in good agreement with first-principles calculations and experimental observations available in literature. Total-energy calculation based on density functional theory can be easily incorporated into the framework of the current method, which is under development. We expect this ab initio actionderived molecular dynamics to contribute even better to finding the diffusion mechanisms as a promising computational method with higher fidelity.

\section{ACKNOWLEDGMENTS}

S.Y.K. was supported by Korea Advanced Institute of Science and Technology. I.-H.L. acknowledges support by the Ministry of Commerce, Industry, and Energy of Korea through "The R\&D Project for Key Technology." S.J. was supported by the University of Wyoming. The authors would like to thank Eunyoung Cho for her help in preparing the manuscript.
*Author to whom correspondence should be addressed; sjun@uwyo.edu

${ }^{1}$ S. Y. Kim, I.-H. Lee, and S. Jun, preceding paper, Phys. Rev. B 76, 245407 (2007).

${ }^{2}$ A. F. Voter, F. Montalenti, and T. C. Germann, Annu. Rev. Mater.
Res. 32, 321 (2002).

${ }^{3}$ I.-H. Lee, J. Lee, and S. Lee, Phys. Rev. B 68, 064303 (2003).

${ }^{4}$ T. Ala-Nissia, R. Ferrando, and S. C. Ying, Adv. Phys. 51, 949 (2002).

${ }^{5}$ Z. Zhang and M. G. Lagally, Science 276, 377 (1997). 
${ }^{6}$ A. G. Naumovets and Z. Zhang, Surf. Sci. 500, 414 (2002).

${ }^{7}$ M. Giesen, Prog. Surf. Sci. 68, 1 (2001).

${ }^{8}$ G. Ehrlich and F. G. Hudda, J. Chem. Phys. 44, 1039 (1966).

${ }^{9}$ R. L. Schwoebel, J. Appl. Phys. 40, 614 (1969).

${ }^{10}$ F. Cleri and V. Rosato, Phys. Rev. B 48, 22 (1993).

${ }^{11}$ J. Li, Modell. Simul. Mater. Sci. Eng. 11, 173 (2003).

${ }^{12}$ D. Passerone and M. Parrinello, Phys. Rev. Lett. 87, 108302 (2001).

${ }^{13}$ Y. Suzuki, H. Kikuchi, and N. Koshizuka, Jpn. J. Appl. Phys., Part 2 27, L1175 (1988).

${ }^{14}$ T. T. Tsong, Prog. Surf. Sci. 64, 199 (2000).

${ }^{15}$ J. Vrijmoeth, H. A. van der Vegt, J. A. Meyer, E. Vlieg, and R. J.
Behm, Phys. Rev. Lett. 72, 3843 (1994).

${ }^{16}$ K. Bromann, H. Brune, H. Röder, and K. Kern, Phys. Rev. Lett. 75, 677 (1995).

${ }^{17}$ T. Maroutian, L. Douillard, and H.-J. Ernst, Phys. Rev. Lett. 83, 4353 (1999).

${ }^{18}$ O. Pierre-Louis, M. R. D’Orsogna, and T. L. Einstein, Phys. Rev. Lett. 82, 3661 (1999).

${ }^{19}$ M. Rusanen, I. T. Koponen, J. Heinonen, and T. Ala-Nissila, Phys. Rev. Lett. 86, 5317 (2001).

${ }^{20}$ J. Merikoski, I. Vattulainen, J. Heinonen, and T. Ala-Nissila, Surf. Sci. 387, 167 (1997).

${ }^{21}$ G. S. Bales and A. Zangwill, Phys. Rev. B 41, 5500 (1990). 